\title{
The Influence of Atlantic Sea Surface Temperature Anomalies on the North Atlantic Oscillation*
}

\author{
Andrew W. Robertson, ${ }^{+}$Carlos R. Mechoso, and Young-Joon Kim \\ Department of Atmospheric Sciences, University of California, Los Angeles, Los Angeles, California
}

(Manuscript received 8 May 1998, in final form 9 March 1999)

ABSTRACT

\begin{abstract}
The influence of Atlantic sea surface temperature (SST) anomalies on the atmospheric circulation over the North Atlantic sector during winter is investigated by performing experiments with an atmospheric general circulation model. These consist of a 30-yr run with observed SST anomalies for the period 1961-90 confined geographically to the Atlantic Ocean, and of a control run with climatological SSTs prescribed globally. A third 30 -yr integration with observed SSTs confined to the South Atlantic is made to confirm present findings.

The simulated interannual variance of 500-hPa wintertime geopotential heights over the North Atlantic attains much more realistic values when observed Atlantic SSTs are prescribed. Circulation patterns that resemble the positive phase of the North Atlantic oscillation (NAO) become more pronounced in terms of the leading EOF of winter means, and a cluster analysis of daily fields. The variance of an interannual NAO index increases by fivefold over its control value. Atlantic SST variability is also found to produce an appreciable rectified response in the December-February time mean.

Interannual fluctuations in the simulated NAO are found to be significantly correlated with SST anomalies over the tropical and subtropical South Atlantic. These SST anomalies are accompanied by displacements in the simulated summer monsoonal circulation over South America and the cross-equatorial regional Hadley circulation.
\end{abstract}

\section{Introduction}

Interannual-to-decadal variability of the atmosphere over the North Atlantic sector in winter is characterized by the so-called North Atlantic oscillation (NAO) teleconnection pattern (Walker and Bliss 1932; van Loon and Rogers 1978; Hurrell 1995). The classic NAO pattern is defined by correlations between the mean sea level pressure (SLP) field and the NAO index, measured in terms of the difference of the standardized anomaly SLP over Portugal minus that over Iceland. The NAO consists primarily of a zonally elongated north-south pressure dipole, with a predominantly equivalent barotropic vertical structure. The nodal line of the dipole lies approximately along the axis of the mean jet stream over the North Atlantic; swings in the NAO are asso-

\footnotetext{
* UCLA Institute of Geophysics and Planetary Physics Publication Number 5186.

+ Additional affiliation: Institute of Geophysics and Planetary Physics, University of California, Los Angeles, Los Angeles, California.

Corresponding author address: Dr. Andrew W. Robertson, Department of Atmospheric Sciences, University of California, Los Angeles, 405 Hilgard Avenue, Los Angeles, CA 90095-1565.

E-mail: andy@atmos.ucla.edu
}

ciated with fluctuations in the meridional pressure gradient and the position and strength of the jet. Since the 1960s, the NAO index has exhibited large decadal swings superimposed on an upward trend (Hurrell 1995). These have been accompanied by pronounced anomalies in temperature and precipitation over Europe (Moses et al. 1987; Parker and Folland 1988).

The dynamics of the NAO and its interannual and longer-term fluctuations are still largely unknown. Evidence from general circulation models (GCMs) suggests that the NAO is an intrinsic mode of the atmosphere, with an essentially intraseasonal timescale (Saravanan 1998). The dipole pattern may result from averaging over several of the atmosphere's preferred patterns of variability (Cheng and Wallace 1993). Anomalies in the NAO can persist for several consecutive years, due either simply to random fluctuations (Robertson et al. 2000) or possibly the influence of SST anomalies. Bjerknes (1964) hypothesized that fluctuations in the NAO index on interannual timescales and longer are associated with ocean-atmosphere interaction. Deser and Blackmon (1993) and others found an approximately 12-yr cycle in SSTs off the east coast of North America, with concurrent changes in atmospheric circulation. The location of these SST anomalies coincides with the Gulf Stream, suggesting that changes in ocean-gyre transport may be causing them. Using a 
coupled ocean-atmosphere GCM, Grötzner et al. (1998) found evidence of this scenario, whereby midlatitude SST anomalies influence the NAO, which then drives changes in the strength of the subtropical ocean gyre and its northward heat transport.

The midlatitude atmosphere clearly forces large SST anomalies through fluctuations in the surface winds, temperatures, and humidities (e.g., Cayan 1992). However, the reverse influence of Atlantic SST anomalies on the atmospheric circulation over the North Atlantic remains poorly understood. Several atmospheric GCM studies have investigated the impact of prescribed northwest-Atlantic SST anomalies, but have failed to reach a consensus. Palmer and Sun (1985) found an equivalent barotropic ridge centered downstream of a prescribed warm SST anomaly over the northwest Atlantic. Peng et al. (1995) found a marked seasonality with a ridge similar to Palmer and Sun's (1985) in November, but a trough during January. Robertson et al. (2000) found differing responses in two 10-yr-long experiments with the same SST anomaly. Using a 30-yr GCM integration forced with observed SST between $38^{\circ} \mathrm{S}$ and $60^{\circ} \mathrm{N}$, Lau and Nath (1990) found an NAO-like pattern to be substantially correlated with SST fluctuations over the tropical South Atlantic. The impact of the El Niño-Southern Oscillation on the North Atlantic appears to be weak (van Loon and Rogers 1981; Chen 1982; Graham et al. 1994; Lau and Nath 1994).

The goal of the present study is to investigate the sensitivity of the atmospheric circulation over the North Atlantic to SST variations within the basin of the North and South Atlantic Oceans. Our strategy is based on the detailed analysis of three 30-yr-long atmospheric GCM integrations. In the first, SSTs follow their seasonally varying climatology everywhere. The second experiment is identical to the control, except that observed SSTs are prescribed over the Atlantic Ocean, with climatology elsewhere. A third integration is made to confirm our findings, with observed SST variations confined to the South Atlantic. This simple strategy allows the influence of the Atlantic SST variations to be isolated while eliminating potential contamination by SST anomalies over the Pacific and other oceans. Our approach contrasts with studies in which observed SST variations are prescribed globally.

The paper is structured as follows. In section 2, we outline the GCM and describe the experimental design. In section 3, we document the simulated variability in terms of winter (December-February; DJF hereafter) averages of 500-hPa geopotential height fields. To examine the model atmosphere's covariability with SST, a singular value decomposition (SVD) analysis of winter means is performed in section 4 . The main finding is a correlation between the model's NAO and SST anomalies over the South Atlantic. The interhemispheric teleconnection is examined in detail in section 5. In section 6 , we examine model variability in terms of a cluster analysis of 10-day low-pass filtered daily 700-hPa height maps. We conclude with a summary and discussion in section 7 .

\section{The GCM experiments and time-mean circulation}

The model used in this study is the University of California, Los Angeles, atmospheric GCM, originally developed by Y. Mintz and A. Arakawa in the 1960 s and revised and updated continuously since then. The configuration (version 6.8) is similar to the one described in Kim (1996) with the following further upgrades as used by Kim et al. (1998), more details of these upgrades may also be found in Yu et al. (1997) and online at http://www.atmos.ucla.edu/esm. The shortwave radiation absorption by water vapor in the Katayama (1972) parameterization scheme is computed following Manabe and Möller (1961). Vertical mixing of momentum in dry convectively unstable layers is parameterized (J. D. Farrara 1997, personal communication), and the climatological distribution of ozone is prescribed from Li and Shine (1995). In addition, moist processes in the boundary layer and moisture exchange with the layer above have been revised ( $\mathrm{Li}$ and Arakawa 1997), resulting in greatly improved surface latent heat fluxes and boundary layer stratus cloud.

We use a relatively coarse resolution of $4^{\circ}$ lat $\times 5^{\circ}$ long, and 15 layers in the vertical with the top at $1 \mathrm{mb}$. Similar horizontal resolution has often been used in recent GCM studies of the atmospheric sensitivity to SST variations (Lau and Nath 1990, 1994, 1996; Graham et al. 1994), as well as in sensitivity studies of the storm track to increasing greenhouse-gas concentrations (Lunkeit et al. 1996). The main structural features of synoptic-scale eddies can be captured quite realistically even with coarse resolution (Metz and Lu 1990).

Two main 30-yr integrations were made, with the SST distributions computed from the GISST2 dataset (Rayner et al. 1995) for the period 1961-90; each run is initialized with the atmospheric state on 1 October 1982. The control run (CTRL hereafter) uses the 30-yr climatological averages of SST for each calendar month (interpolated linearly in time by the model). In the second experiment (ATL hereafter), observed monthly SST values are prescribed over the Atlantic Ocean $\left(90^{\circ} \mathrm{S}-90^{\circ} \mathrm{N}, 75^{\circ} \mathrm{W}-\right.$ $25^{\circ} \mathrm{E}$ ), with control values elsewhere. A third 30-yr simulation was made a posteriori to confirm the findings from ATL. In this additional experiment (SATL hereafter), observed monthly SST values are prescribed over the South Atlantic Ocean only $\left(90^{\circ} \mathrm{S}-10^{\circ} \mathrm{N}, 75^{\circ} \mathrm{W}-25^{\circ} \mathrm{E}\right)$, with control values everywhere else. All model analyses are made on the model grid, with the GISST SSTs averaged onto a similar $4^{\circ}$ lat $\times 5^{\circ}$ long grid.

Figure 1 shows the DJF climatological mean 500-hPa geopotential height fields from the CTRL and ATL experiments, as well as from the National Centers for Environmental Prediction-National Center for Atmospheric Research (NCEP-NCAR) 40-Year Reanalysis data 
a) CTRL

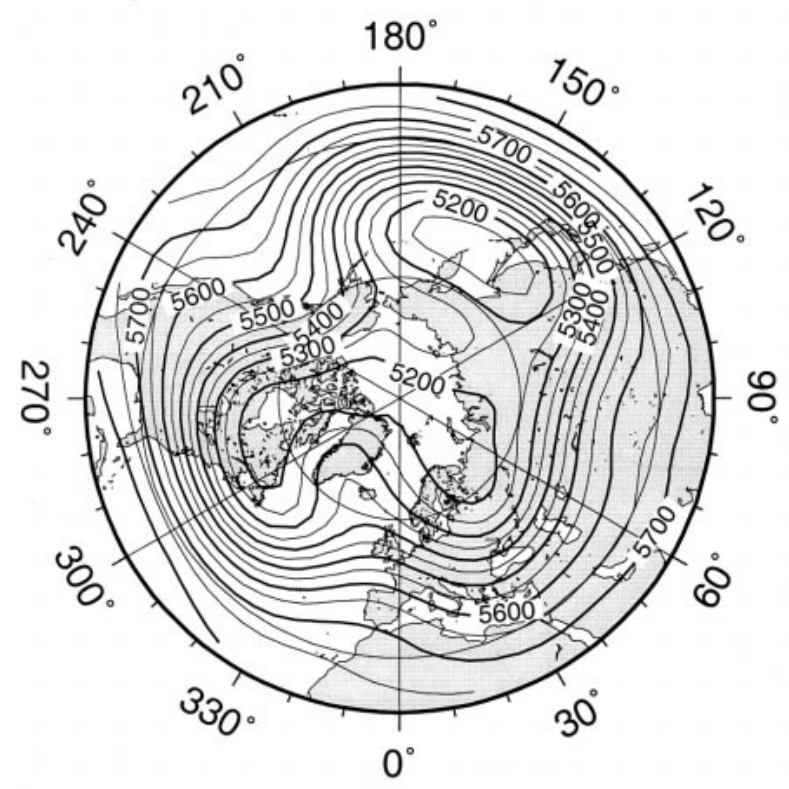

c) OBS

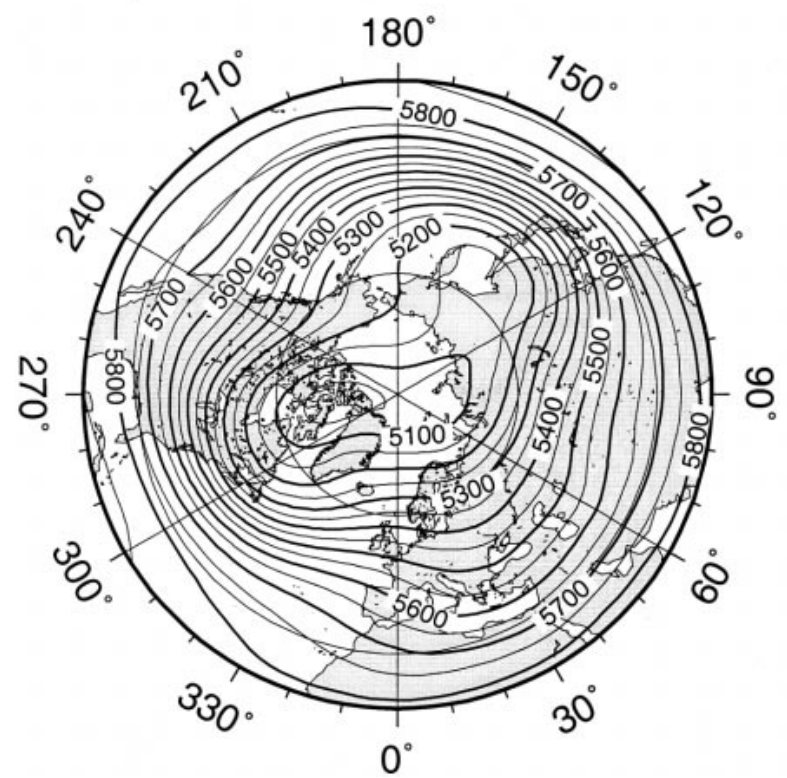

b) ATL

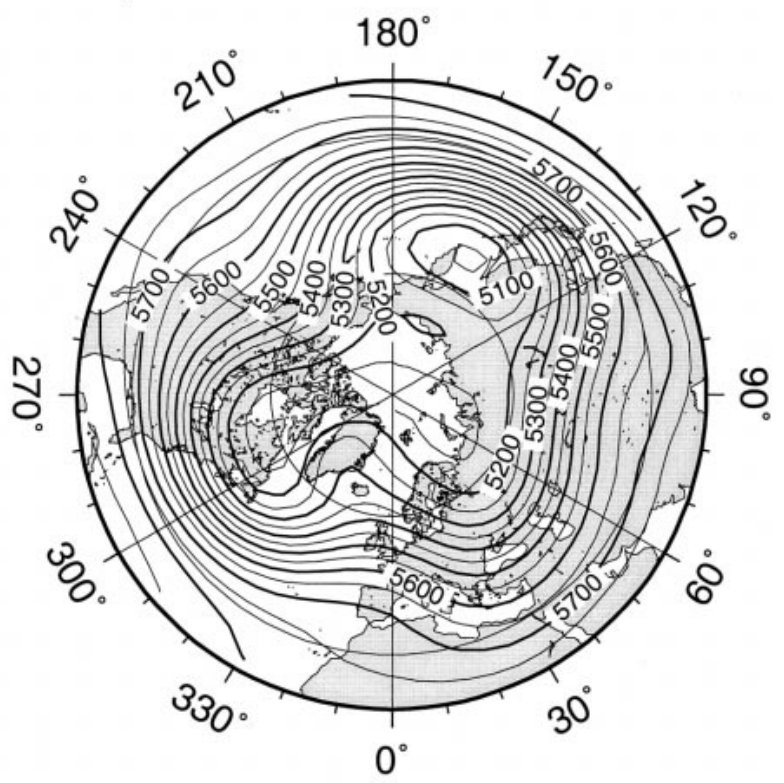

d) ATL-CTRL

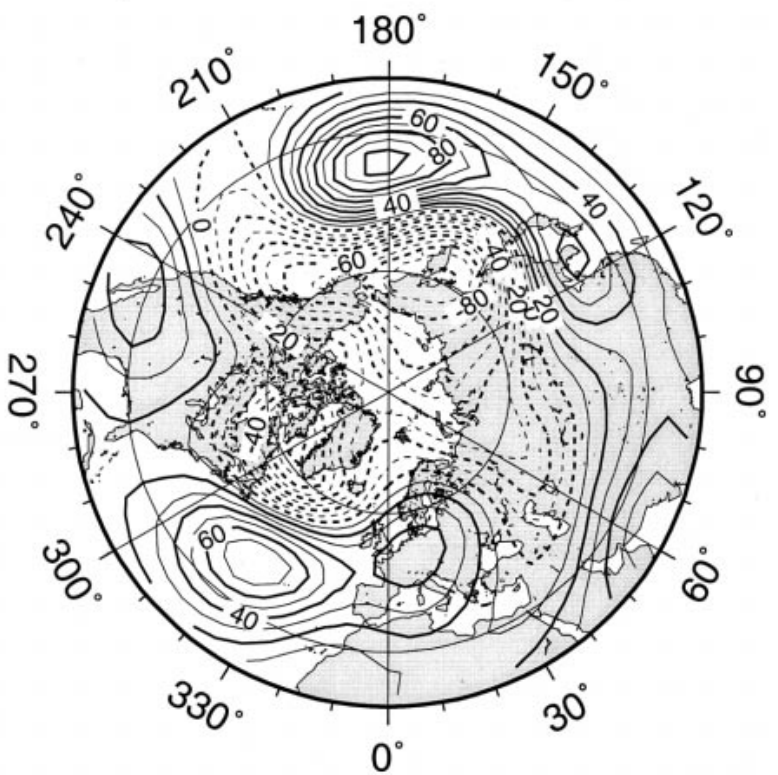

FIG. 1. The time-mean 500-hPa DJF geopotential height 1961/62-1989/90 from (a) CTRL simulation, (b) ATL simulation, and (c) NCEPNCAR reanalysis data; (d) ATL-minus-CTRL difference. Contour interval is (a)-(c) $50 \mathrm{~m}$ and (d) $10 \mathrm{~m}$. All maps are of the Northern Hemisphere, north of $20^{\circ} \mathrm{N}$.

(given on a $2.5^{\circ}$ lat $\times 2.5^{\circ}$ long grid) corresponding to the period 1961-90 (OBS hereafter). The model performs reasonably well compared to other current GCMs (cf. D'Andrea et al. 1998). However, the climatological mean troughs over the western Pacific and eastern Canada are noticeably more realistic in ATL (Fig. 1b) than CTRL (Fig. 1a), where both troughs extend too far east.
The mean height differences between ATL and CTRL at $500 \mathrm{mb}$ are shown in Fig. 1d. The rectified effect of Atlantic SST anomalies is substantial, with maxima over both ocean sectors, and a large zonally symmetric hemispheric component. A pointwise Student's t-test applied to Fig. 1d (not shown) indicates all the major features to be significant at the $99 \%$ confidence level. 
a) CTRL

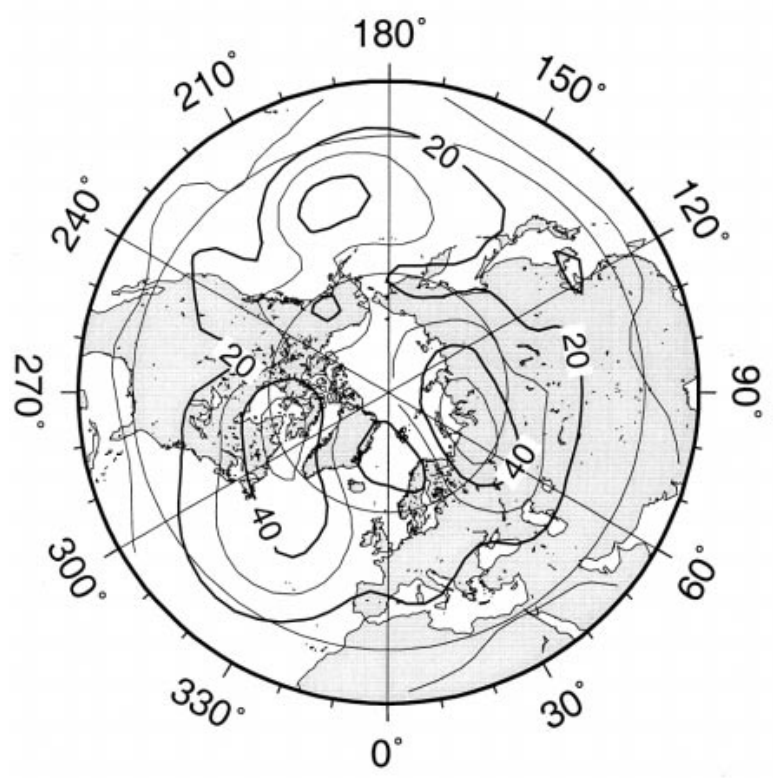

c) OBS

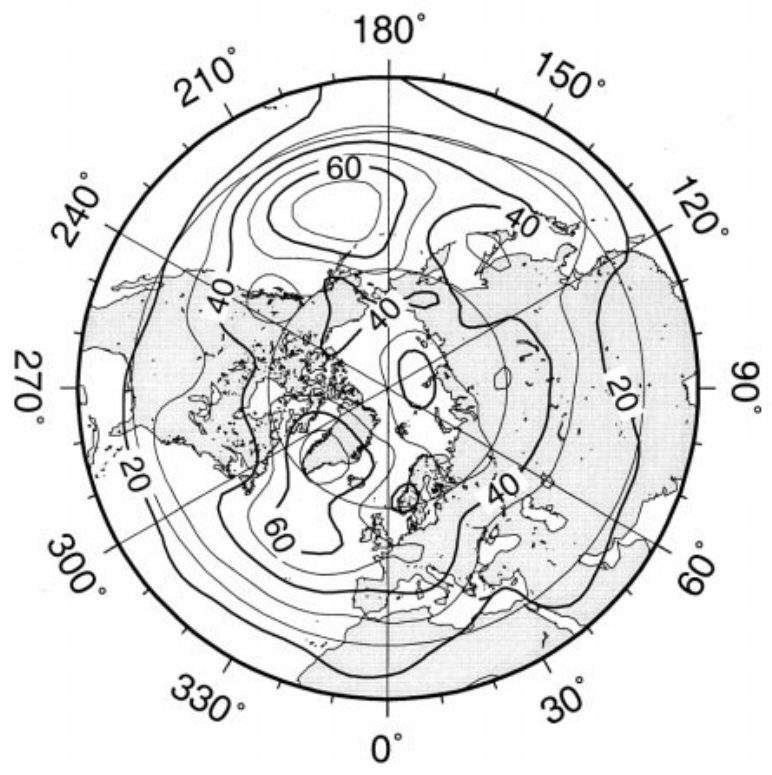

\section{Atmospheric variability I: Winter means \\ a. Variance}

Figure 2 presents the standard deviations of $500-\mathrm{hPa}$ geopotential height December-February (DJF) means. The CTRL simulation exhibits three centers of variability that are located quite realistically, although the variance is underestimated. The ATL experiment shows both a local increase in variance to near-realistic magnitudes over the North Atlantic, and a remote increase over the North Pacific. Despite the model's rather coarse horizontal resolution, interannual variability is not se- b) ATL

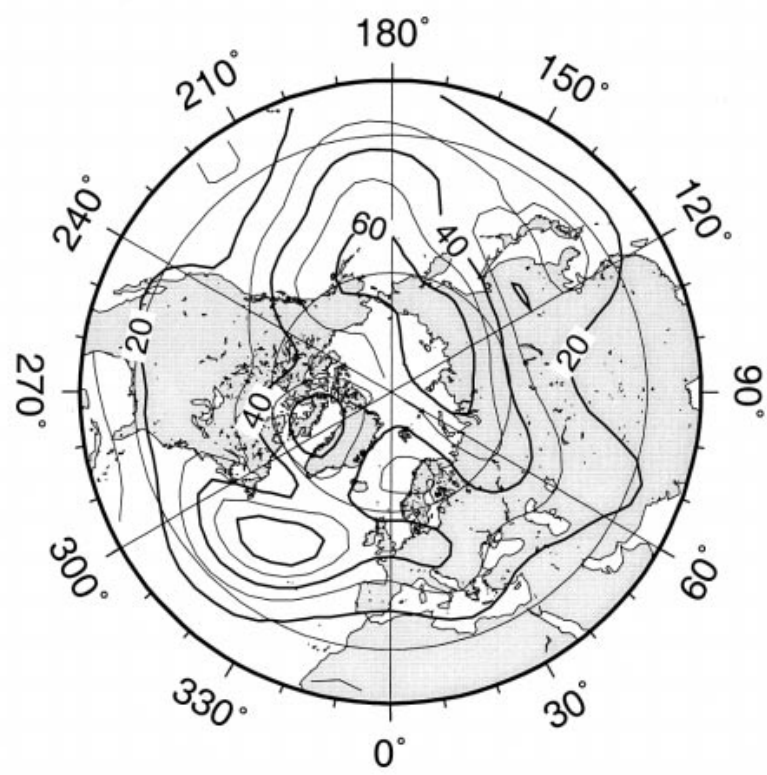

FIG. 2. The std dev of 500-hPa geopotential height DJF means, 1961/62-1989/90, from (a) CTRL simulation, (b) ATL simulation, and (c) NCEP-NCAR reanalysis data. The contour interval is $10 \mathrm{~m}$.

riously underestimated in ATL. This is also true of the intraseasonal variance (10-90 days), which matches observed values over the North Atlantic, while the 2.56-day bandpass variance, characterized by synopticscale waves, is underestimated by up to $40 \%$.

\section{b. EOF analysis}

To identify the spatial structures that characterize interannual variability in the simulations, we begin with a standard empirical orthogonal function (EOF) analysis of DJF-mean maps of 500-hPa geopotential height over 
a) CTRL

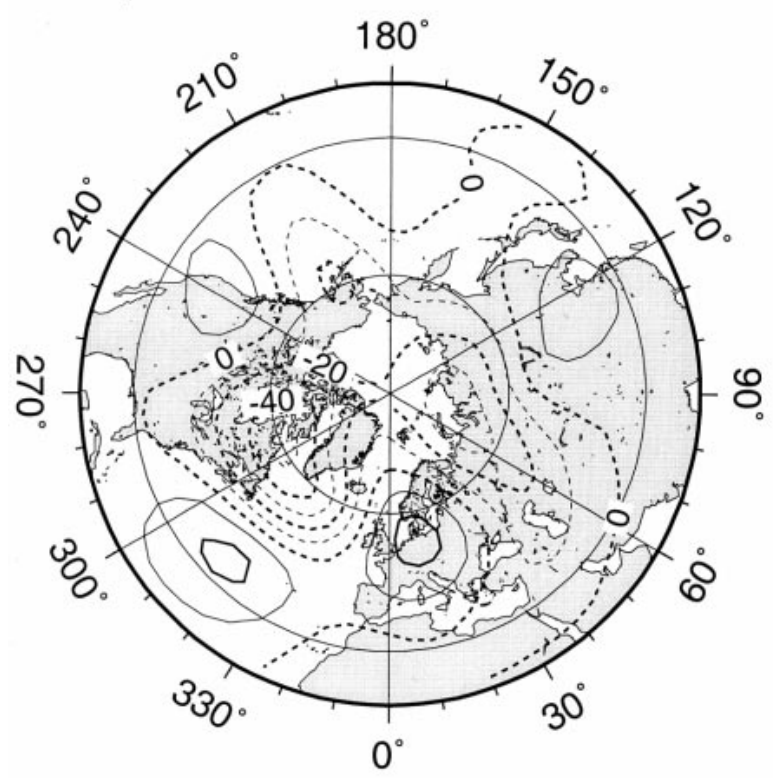

c) OBS

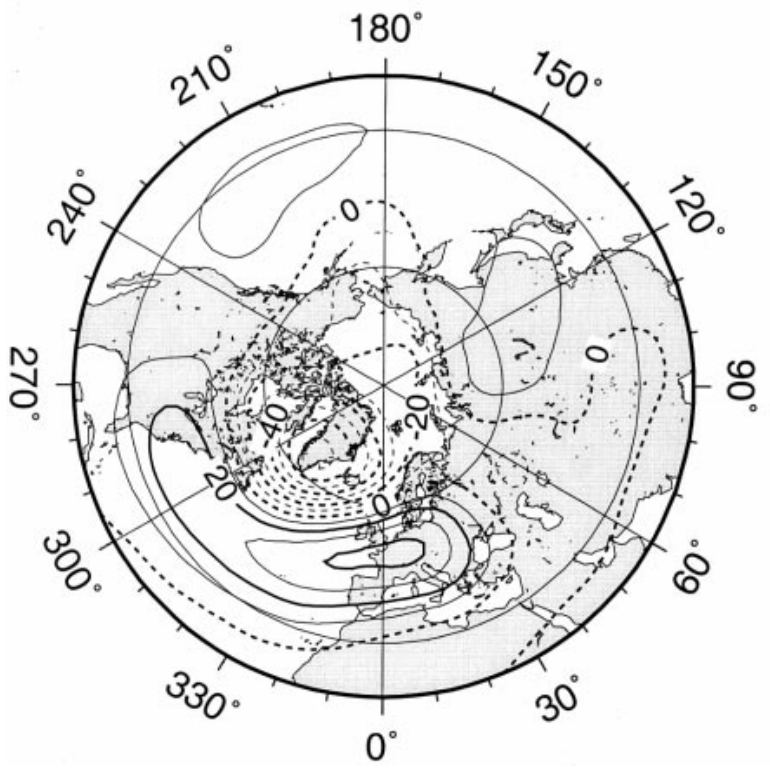

the North Atlantic sector $\left(20^{\circ}-90^{\circ} \mathrm{N}, 90^{\circ} \mathrm{W}-40^{\circ} \mathrm{E}\right)$. Figure 3 shows the leading EOF for each simulation and OBS. The EOFs are plotted in terms of hemispheric maps of $500-\mathrm{hPa}$ height regressed onto the amplitude time series of the leading North Atlantic EOF. The leading EOF accounts for $46.6 \%$ (CTRL), 50.0\% (ATL), and $43.3 \%$ (OBS) of the variance over the Atlantic sector. Hemispheric maps are plotted to identify any extraAtlantic aspects. The leading observed interannual Atlantic-sector EOF (Fig. 3c) closely resembles the canonical NAO (e.g., Hurrell 1995). The model's NAO is strongest over the northwest Atlantic, with a much more

\section{b) ATL}

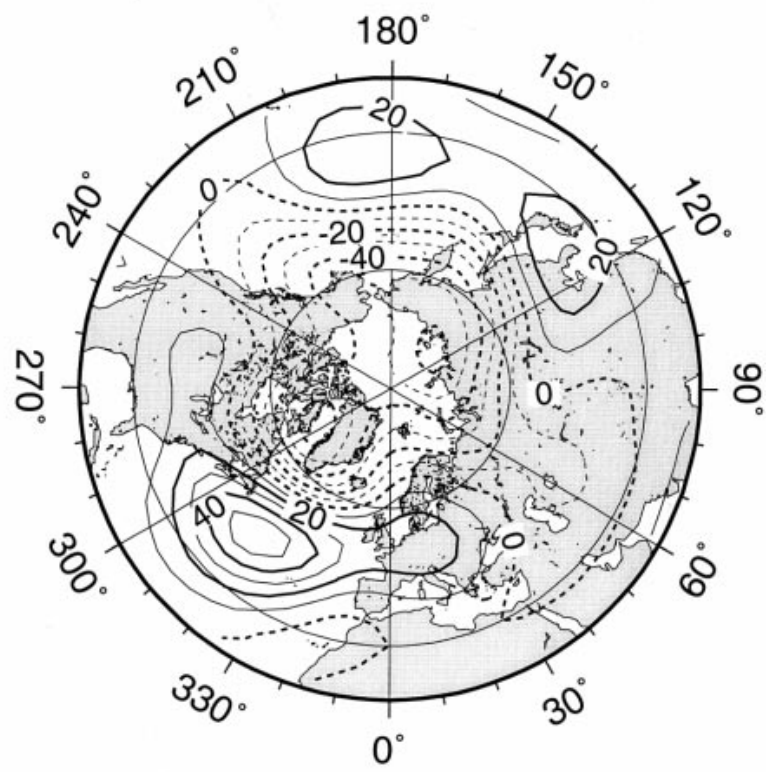

FIG. 3. The leading North Atlantic EOF of 500-hPa geopotential height DJF means, 1961/62-1989/90, from (a) CTRL simulation, (b) ATL simulation, and (c) NCEP-NCAR reanalysis data. The EOFs were computed over the region $20^{\circ}-90^{\circ} \mathrm{N}, 90^{\circ} \mathrm{W}-40^{\circ} \mathrm{E}$, and are plotted in terms of hemispheric regression maps of the respective principle component with the $500-\mathrm{hPa}$ height field. The contour interval is $10 \mathrm{~m}$. realistic north-south dipole in ATL (Fig. 3b) than the control (Fig. 3a). The ATL EOF exhibits an exaggerated zonally symmetric hemispheric component that bears some resemblance to the difference in means between the ATL and CTRL simulations in Fig. 1d. An appreciable zonally symmetric component is characteristic of the "Arctic oscillation," which has been identified in GCMs and observed data (Kitoh et al. 1996; Thompson and Wallace 1998). In all three cases, EOF2 (not shown) accounts for about $20 \%$ of the variability and consists predominantly of a monopole centered over the North Atlantic. 


\section{Covariability with SST}

We next perform an analysis of cross-covariance between the GISST Atlantic SST and simulated geopotential height fields in the ATL experiment using an SVD. The cross-covariance matrix was constructed between winter means (DJF 1961/62-1989/90) of SST over the Atlantic $\left(40^{\circ} \mathrm{S}-70^{\circ} \mathrm{N}\right)$ and $500-\mathrm{hPa}$ height over the North Atlantic sector $\left(20^{\circ}-90^{\circ} \mathrm{N}, 90^{\circ} \mathrm{W}-40^{\circ} \mathrm{E}\right)$, followed by an SVD of the matrix. Prior to construction of this covariance matrix, the gridpoint data were multiplied by the square root of the cosine of latitude, so that variances would be weighted by area (Branstator 1987), and then truncated by projecting onto the leading 10 EOFs.

Just as EOF analysis optimally partitions the variance of a single field into a sequence of orthogonal vectors, the leading pairs of singular vectors in an SVD maximize the (squared) cross-covariance between two fields (e.g., Bretherton et al. 1992). Pairs of time series are obtained-consisting of the expansion coefficients of each pair of singular vectors-whose squared covariance is maximized, though their correlation is not, as is the case with canonical correlation analysis (CCA). Nonetheless SVD and CCA generally produce very similar results (Bretherton et al. 1992), while SVD is considerably more straightforward and transparent to apply. The SVD method has been used and discussed extensively over the past few years in the meteorological literature (Wallace et al. 1992; Newman and Sardeshmukh 1995; Cherry 1997).

The leading SVD mode accounts for $77.3 \%$ of the squared covariance between Atlantic SSTs and North Atlantic geopotential heights (Fig. 4) with the second mode accounting for just $11.4 \%$ (not shown). The maps in Figs. $4 \mathrm{a}$ and $4 \mathrm{~b}$ are homogeneous correlation maps between the given field and its expansion-coefficient time series in Fig. 4c; the latter are derived by projecting the singular vectors onto the respective original data fields. To identify remote associations, the correlations in Figs. $4 \mathrm{a}$ and $4 \mathrm{~b}$ are not restricted to the geographical domains used in the SVD analysis. The results of the SVD were found not to be very sensitive to extending the analysis domain of either SST or geopotential height to $60^{\circ} \mathrm{S}$.

The SST field (Fig. 4a) exhibits large positive correlations $(>+0.8)$ over the equatorial Atlantic extending into the South Atlantic, with smaller magnitudes in the North Atlantic. This SST pattern accounts for $27.8 \%$ of the interannual variance of GISST SST over the analysis domain. The accompanying height field (Fig. 4b) shows an NAO-like dipole over the western North Atlantic and a pronounced zonally symmetric hemispheric component, similar to the leading EOF (Fig. 3b); the mode accounts for $47.7 \%$ of the interannual geopotential height field variance. Negative correlations exceed -0.8 over Greenland and the polar regions. Positive corre- lations exceed +0.8 over the western North Atlantic, and also over Korea.

The expansion-coefficient time series (Fig. 4c) are correlated at 0.59 and are dominated by interannual timescales (with a broad spectral peak near $5 \mathrm{yr}$ ) and an upward trend. The 99\% significance level corresponds to a correlation of 0.51 , using a Student's $t$-test with 24 degrees of freedom. All estimates of the effective number of degrees of freedom utilize the autocorrelations of the time series via the method of Davis (1976; see also Chen 1982). Subtracting the linear trend from both geopotential heights and SST at the outset was found to make very little change to the structure and (co)variances of the leading mode.

A significant linear relationship between South Atlantic SSTs and the simulated NAO can also be demonstrated using simple indices. Using DJF averages, an NAO index was constructed from the Greenland-minusAzores 500-hPa height difference (see Fig. 10 below), with an SST index defined by averaging over the tropical South Atlantic $\left(4^{\circ} \mathrm{N}-16^{\circ} \mathrm{S}\right)$. The correlation coefficient between them is 0.45 , which is statistically significant at the $95 \%$ confidence level, with 24 degrees of freedom estimated.

To identify any observed counterpart we have repeated the SVD analysis using the NCEP-NCAR reanalysis geopotential height data in the same domains as above. The leading observed mode (Fig. 5) closely resembles that discussed by Grötzner et al. (1998). Here the configuration of SST and geopotential height correlations in Fig. 5 is consistent with observational evidence that atmosphere-SST covariability over the North Atlantic is largely determined by the atmosphere forcing the ocean (Cayan 1992). Over the South Atlantic, however, the SST correlations in Fig. 5a do bear broad similarity to the model result.

\section{Interhemispheric teleconnections}

To test the robustness of the model's pan-Atlantic mode, a third 30-yr simulation was made, a posteriori, with GISST SSTs (1961-90) confined to the South Atlantic, south of $10^{\circ} \mathrm{N}$, with climatological SSTs prescribed elsewhere (SATL). Figure 6 shows the leading mode of an SVD analysis between DJF means of SST over the South Atlantic $\left(40^{\circ} \mathrm{S}-5^{\circ} \mathrm{N}\right)$ (since North Atlantic SSTs do not vary) and 500-hPa height over the North Atlantic sector in the SATL experiment. The mode is indeed similar in most respects to that found in ATL (Fig. 4). The SVD time series (Fig. 6c) are correlated at $r=0.53$, which is significant at the $95 \%$ level with 18 degrees of freedom. Some discrepancies in pattern occur over Europe, with positive geopotential correlations in Fig. 6b largely confined to the North Atlantic, and over the Arctic where negative correlations are weaker. Constructing simple indices of the NAO and SST over the tropical South Atlantic in the same way as in section 4 yields a correlation coefficient between 
a) SST

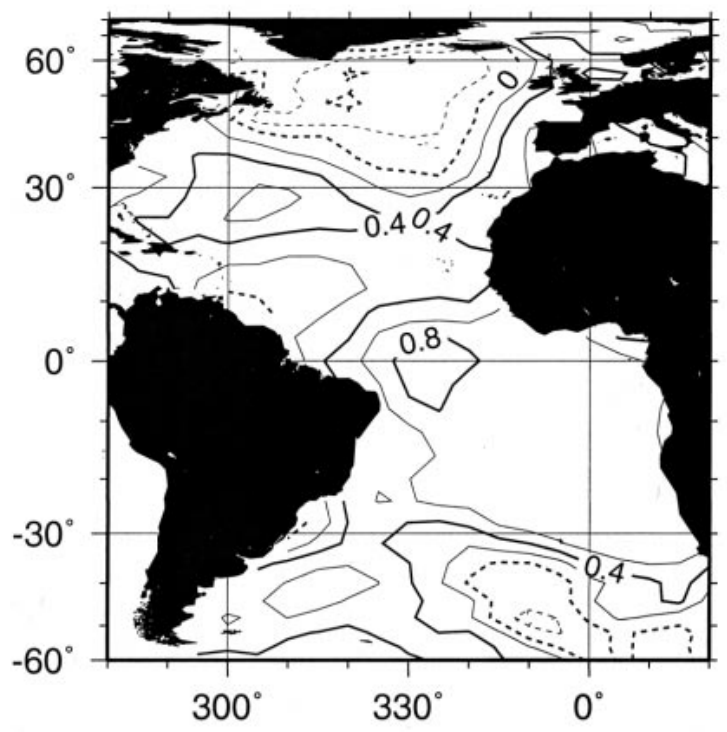

c) Time Series b) Simulated Z-500mb

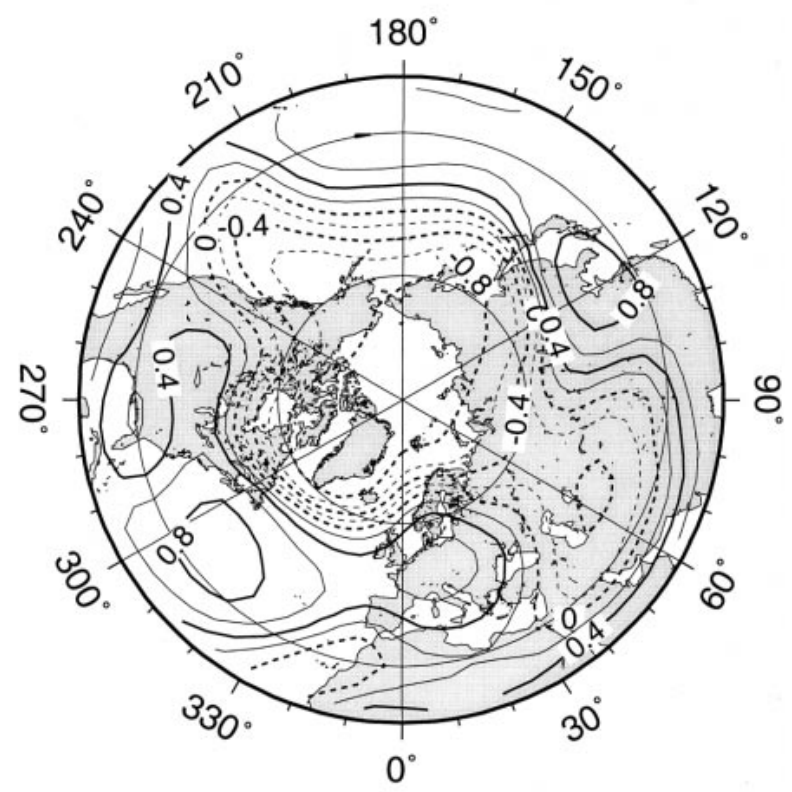

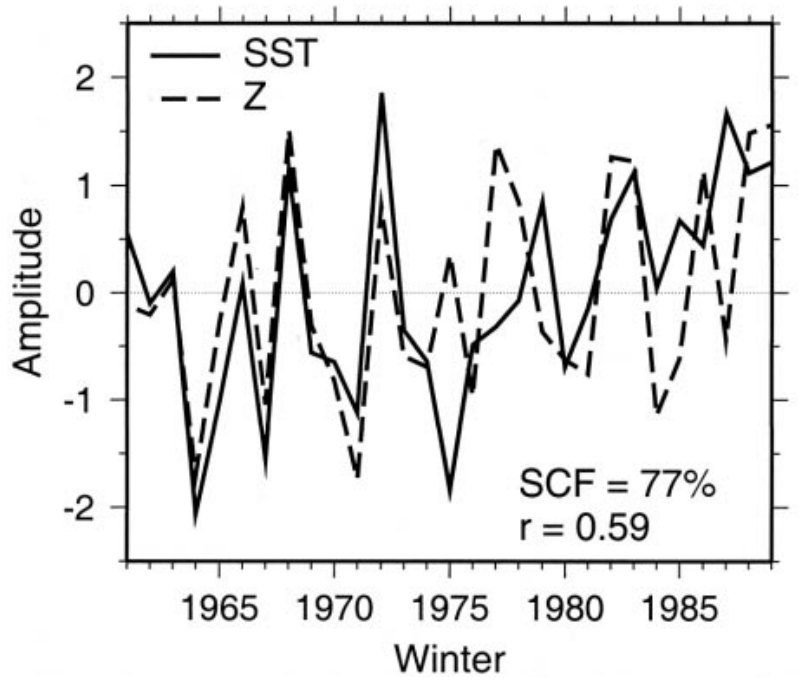

FIG. 4. The leading SVD mode of GISST Atlantic SST $\left(40^{\circ} \mathrm{S}-70^{\circ} \mathrm{N}\right)$ and $500-\mathrm{hPa}$ height over the North Atlantic sector $\left(20^{\circ}-90^{\circ} \mathrm{N}, 90^{\circ} \mathrm{W}-40^{\circ} \mathrm{E}\right)$ from the ATL experiment, using DJF means. (a) and (b) Correlation maps (contour interval: 0.2 ) of SST and 500-hPa heights, with the respective expansion-coefficient time series shown in (c): solid line, SST; dashed line, geopotential height. The correlation maps extend beyond the geographical domains used in the SVD analysis. This mode accounts for $77.3 \%$ of the squared covariance, $27.8 \%$ of the SST variance, and $47.7 \%$ of the geopotential variance. (c) The time series have a correlation coefficient of 0.59 . them of $r=0.39$. This is again statistically significant with greater than $95 \%$ confidence (with 28 degrees of freedom estimated). Repeating the model SVD analysis in section 4 using the same South Atlantic SST domain as that used in Fig. 6 produced very similar results to Fig. 4.

To examine further the interhemispheric teleconnection in Figs. 4 and 6, we construct precipitation and circulation anomaly composites for warm-minus-cold DJF seasons over the South Atlantic, using the SATL simulation. Figure 7 shows mean (Fig. 7a) and anom- alous (Fig. 7b) DJF precipitation maps from the SATL simulation; similar-looking distributions were also obtained from the ATL experiment. The climatological precipitation maximum over Amazonia is quite realistically simulated in both extent and magnitude, while the intertropical convergence zone and the South Atlantic convergence zone (SACZ), though present, are poorly resolved-probably due to the relatively low model resolution. The composite anomalies in Fig. 7b were obtained by subtracting four cold DJF seasons over the South Atlantic from four warm ones (defined by 
a) SST

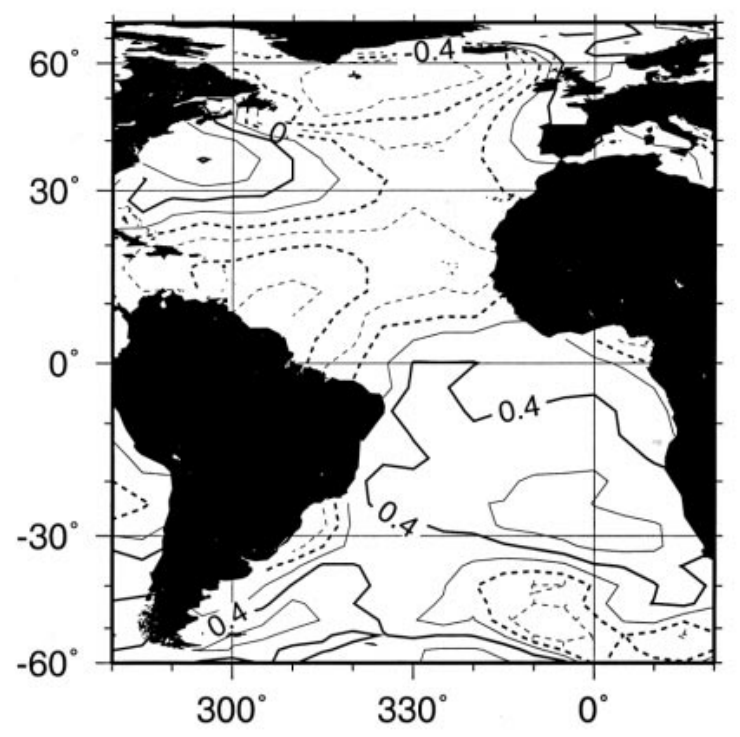

c) Time Series b) NCEP Z-500mb

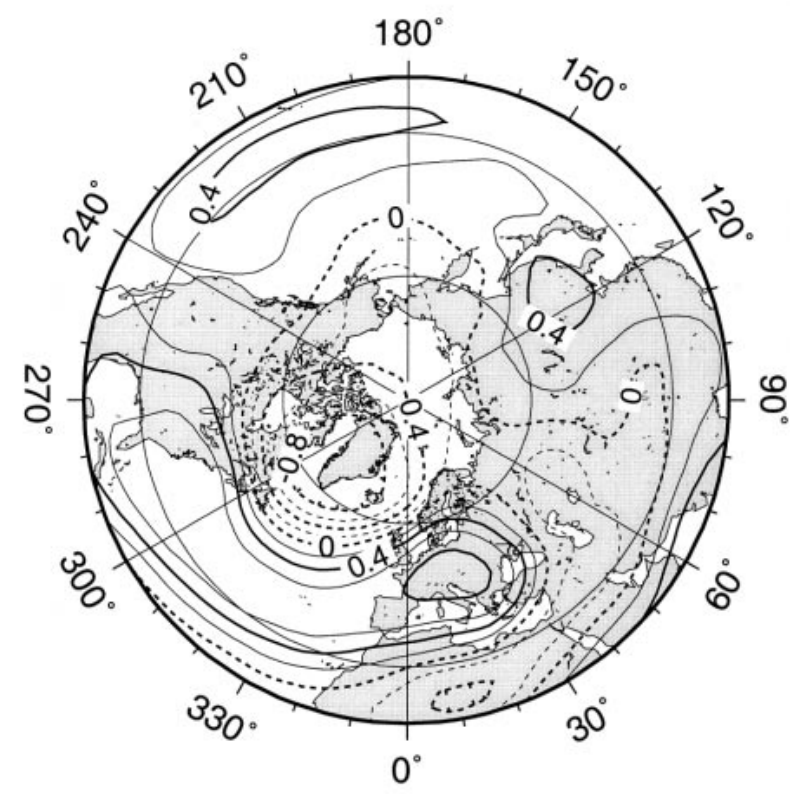

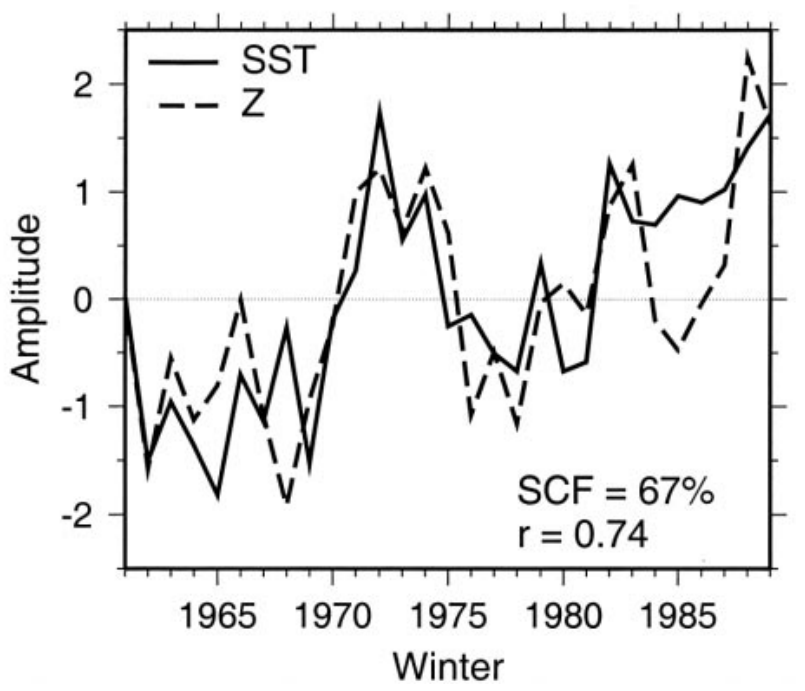

FIG. 5. The leading SVD mode of GISST Atlantic SST $\left(40^{\circ} \mathrm{S}-70^{\circ} \mathrm{N}\right)$ and NCEP-NCAR reanalysis $500-\mathrm{hPa}$ height over the North Atlantic sector $\left(20^{\circ}-90^{\circ} \mathrm{N}, 90^{\circ} \mathrm{W}-40^{\circ} \mathrm{E}\right)$. Details as in Fig. 4. This mode accounts for $67.4 \%$ of the squared covariance, $74.1 \%$ of the SST variance, and $42.1 \%$ of the geopotential variance. (c) The time series have a correlation coefficient of 0.74 .

one-standard-deviation anomalies of the SST time series of the leading SVD mode in Fig. 6c). Shading indicates areas that pass a pointwise Student's $t$-test at the $99 \%$ level. Positive precipitation anomalies are located to the southwest of the Amazonian climatological maximum, with negative anomalies to the east and north of it; together these anomalies represent a southwestward displacement of the South American summer monsoon circulation, with a weakening of the model's SACZ. Composite SST anomalies (not shown) reach $+1.5 \mathrm{~K}$ along $25^{\circ} \mathrm{S}$, while the pattern is similar to the correlation map in Fig. 6a.

Figure 8 shows the streamfunction and divergent wind at $850 \mathrm{mb}$. Consistent with the DJF-mean precipitation maximum, there is strong low-level climatological convergence over Amazonia with centers of compensating divergence over the eastern tropical oceans and in a band between $15^{\circ}$ and $30^{\circ} \mathrm{N}$ (Fig. 8a). Figure $8 \mathrm{~b}$ shows composite anomalies analogous to those in Fig. 7b. The major features in Fig. $8 b$ are significant at 
a) SST

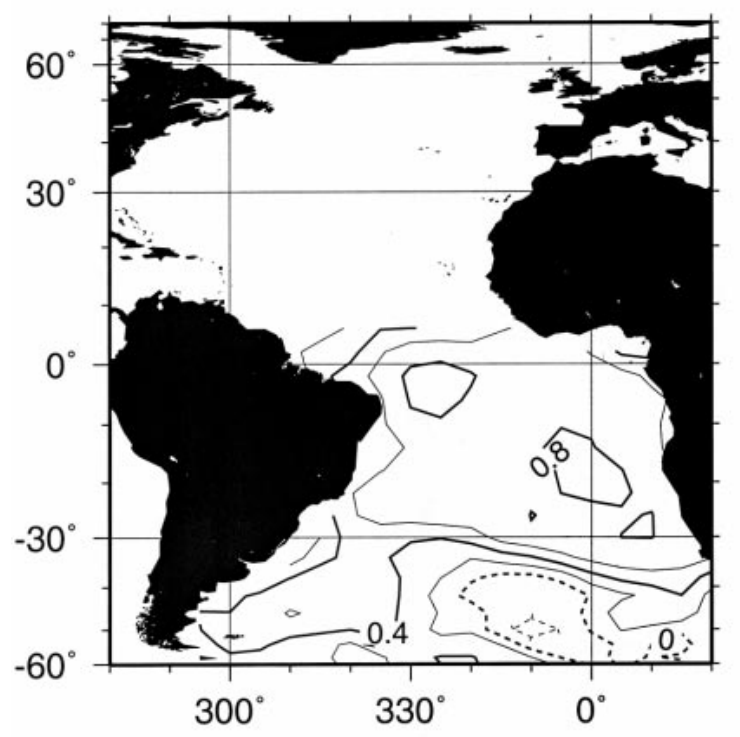

c) Time Series

\section{b) Simulated Z-500mb}

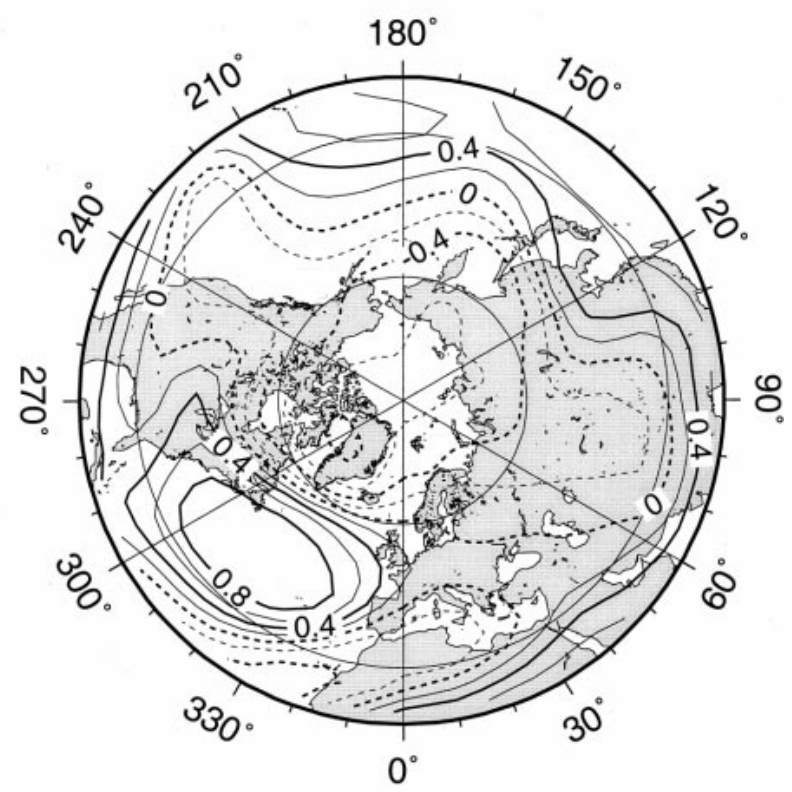

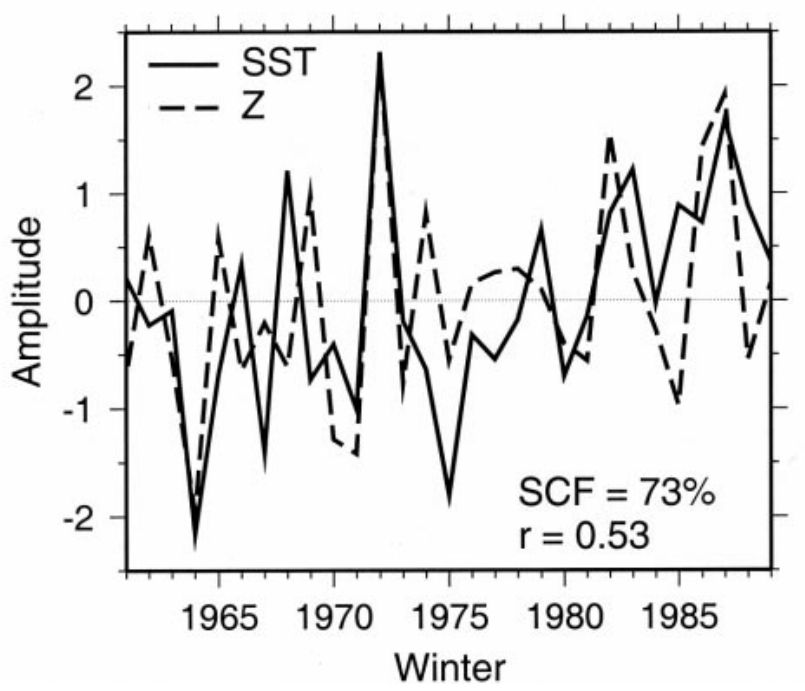

FIG. 6. The leading SVD mode of GISST South Atlantic SST $\left(40^{\circ} \mathrm{S}-5^{\circ} \mathrm{N}\right)$ and $500-\mathrm{hPa}$ height over the North Atlantic sector $\left(20^{\circ}-90^{\circ} \mathrm{N}, 90^{\circ} \mathrm{W}-40^{\circ} \mathrm{E}\right)$ from the SATL experiment. Details as in Fig. 4. This mode accounts for $73.0 \%$ of the squared covariance, $38.7 \%$ of the SST variance, and $38.0 \%$ of the geopotential variance. (c) The time series have a correlation coefficient of 0.53 .

the $99 \%$ level according to a pointwise Student's $t$-test (not shown). There is an anomalous westward intensification of the subtropical anticyclone into southern Brazil and Uruguay, together with anomalous low-level convergence into south-central South America; the latter is consistent with the intensification of the southern portion of the Amazonian convergence zone seen in the precipitation anomalies. Composites of the GCM's latent-plus-sensible heat flux anomalies are weak over the South Atlantic (not shown), and there is little evidence of direct thermal forcing. In the equatorial region, the anomalous surface fluxes are directed into ocean and would thus act to reinforce the warm SST anomalies there.

In the Northern Hemisphere, there is a region of anomalous low-level divergence near $10^{\circ} \mathrm{N}, 60^{\circ} \mathrm{W}$, suggesting that the regional Hadley circulation, with mean ascent over Amazonia and mean descent near $20^{\circ} \mathrm{N}$, is displaced southward, consistent with the southward displacement of South American convection. Figure 9 shows latitudinal profiles of the upper-level 200-hPa flow, averaged zonally between $70^{\circ}$ and $30^{\circ} \mathrm{W}$. The mean 
a) DJF Mean

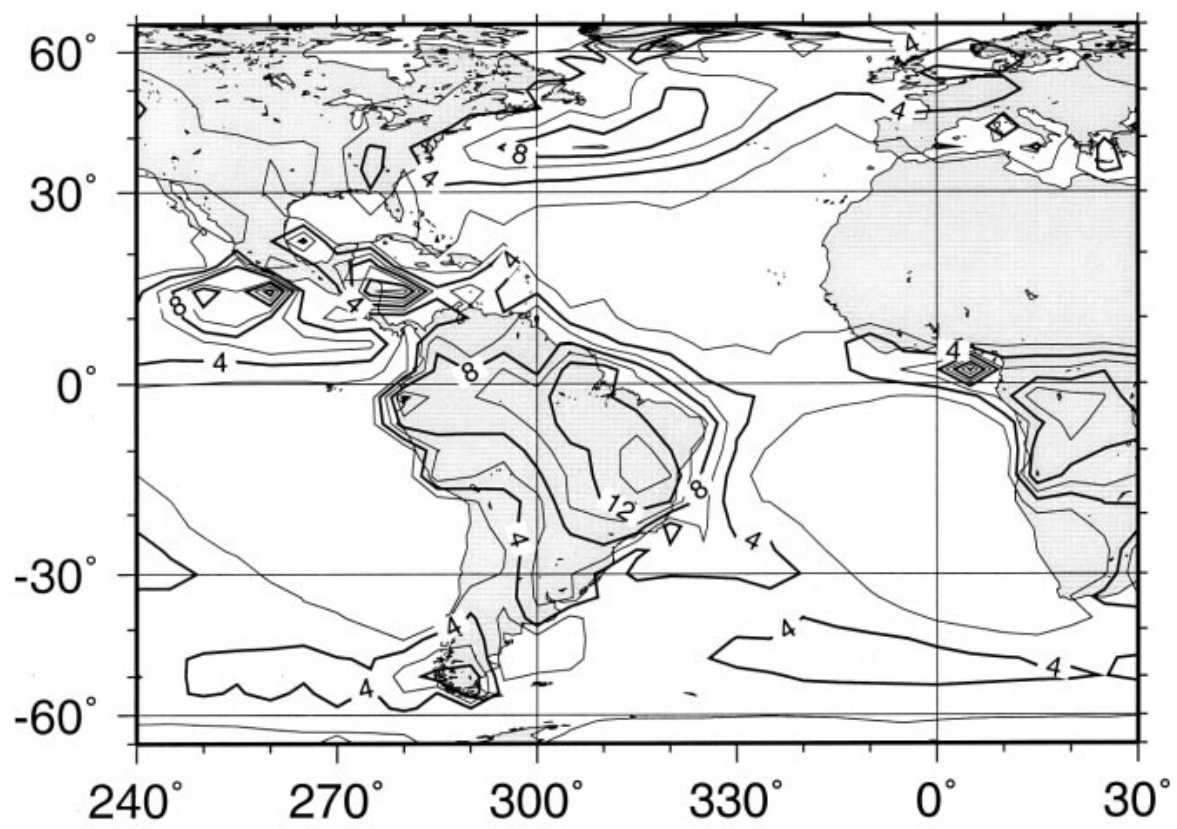

b) Composite Anomalies

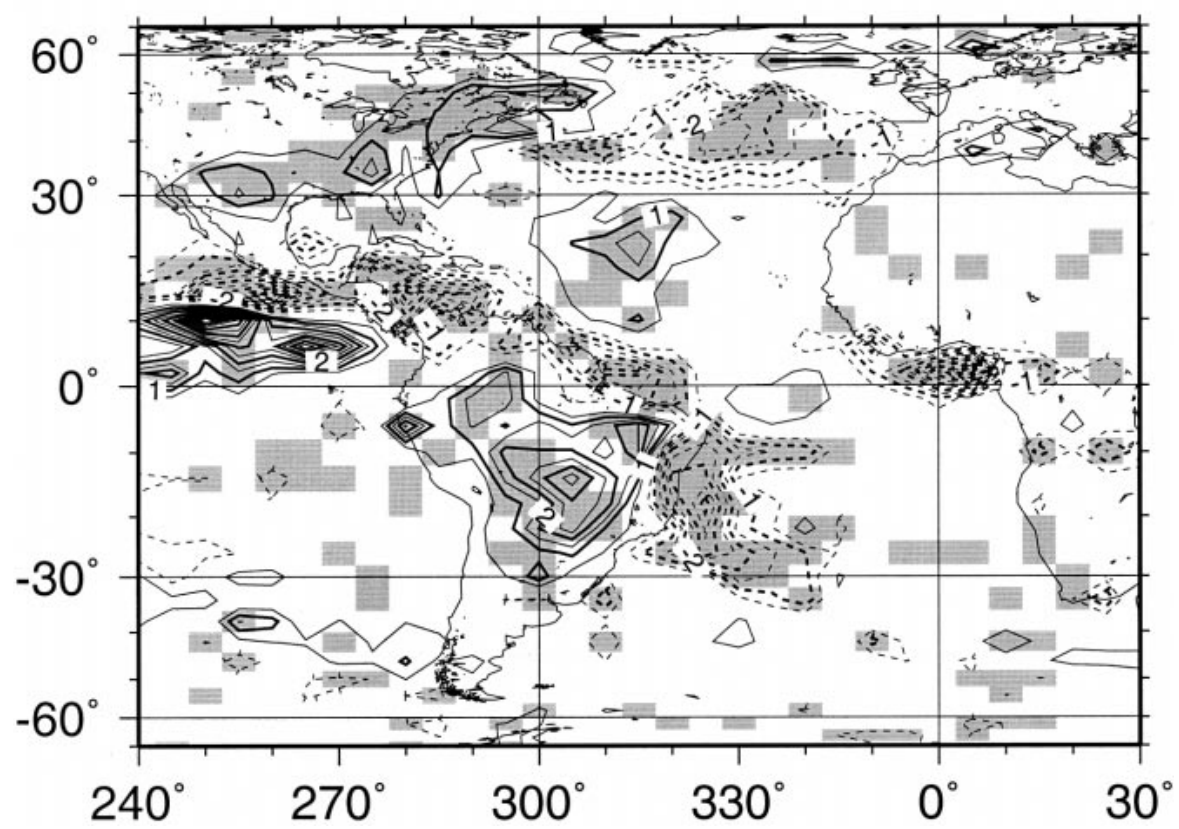

FIG. 7. Precipitation fields from the SATL simulation: (a) DJF mean (contour interval $2 \mathrm{~mm} \mathrm{day}^{-1}$ ), and (b) a composite of warm-minus-cold years over the South Atlantic (contour interval $0.5 \mathrm{~mm}$ day $^{-1}$; zero contour omitted). Eight years are included in the composite, for which the SST time series of the leading SVD mode (Fig. 6c) exceeds one std dev in amplitude. (b) Shading denotes grid points that are significant at the $99 \%$ level according to a $t$ test with 7 degrees of freedom. 


\section{a) DJF Mean}

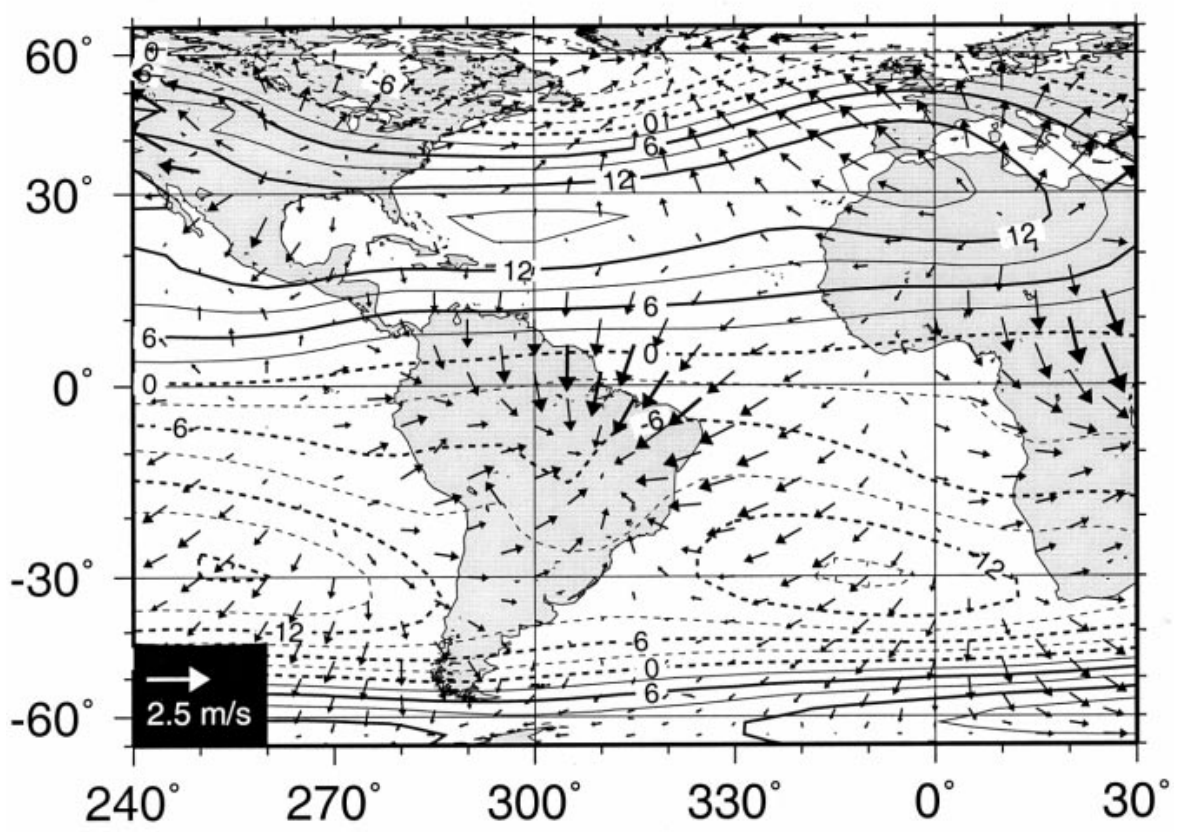

\section{b) Composite Anomalies}

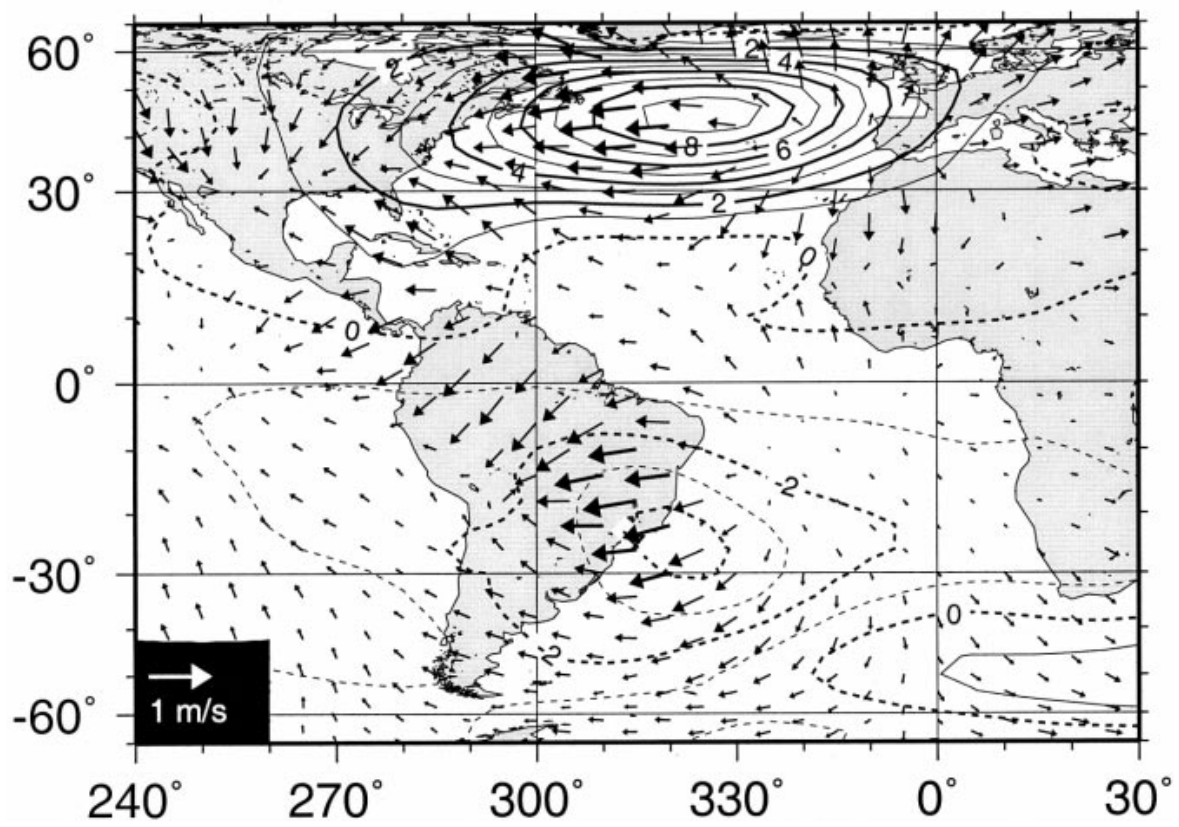

FIG. 8. Streamfunction (contours) and divergent wind (vectors) at $850 \mathrm{mb}$ from the SATL simulation for (a) DJF mean (contour interval $3 \times 10^{6} \mathrm{~m}^{2} \mathrm{~s}^{-1}$ ), and (b) a composite of warm-minus-cold years over the South Atlantic (contour interval $1 \times 10^{6} \mathrm{~m}^{2} \mathrm{~s}^{-1}$ ). The divergent wind vectors are scaled as indicated by the key in each panel. Details as in Fig. 7. 
a) Zonal Wind

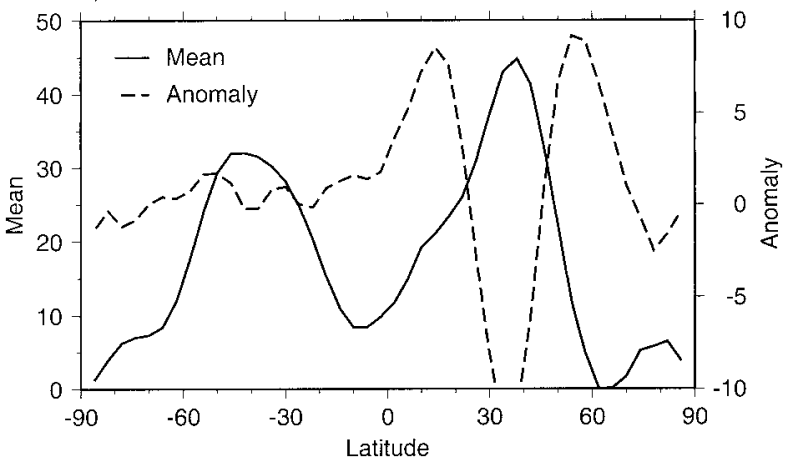

b) Meridional Divergent Wind

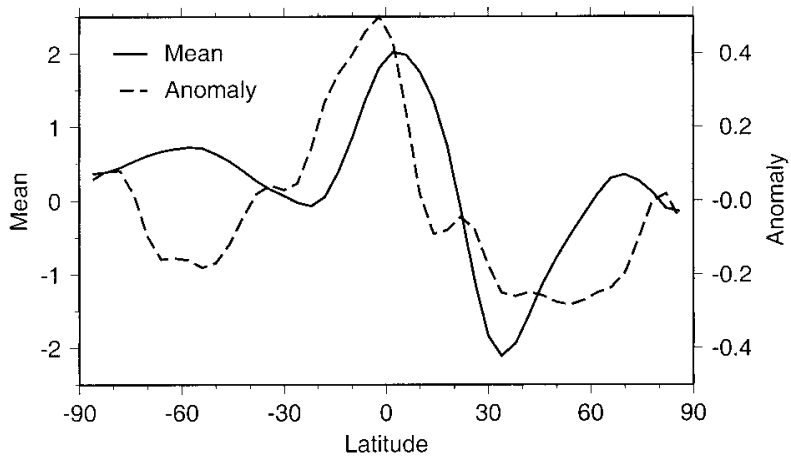

FIG. 9. Meridional profiles at $200 \mathrm{hPa}$ of (a) zonal wind and (b) meridional divergent wind in the SATL experiment, both averaged zonally between $70^{\circ}$ and $30^{\circ} \mathrm{W}$. The solid curves denote the 30 -winter (DJF) mean. The dashed curves denote composites of warm-minuscold years over the South Atlantic. Details as in Fig. 7.

North Atlantic subtropical jet (Fig. 9a, solid line) peaks near $40^{\circ} \mathrm{N}$. Composite (warm minus cold) SST anomalies over the South Atlantic are associated with a deceleration of the jet maximum, with accelerations to both the north and south (dashed line). Profiles of the meridional divergent wind are shown in Fig. 9b. Climatological northward flow associated with the thermally direct cell originating over Amazonia is pronounced between $10^{\circ} \mathrm{S}$ and $20^{\circ} \mathrm{N}$ (solid line). Composite (warm minus cold) SST anomalies over the South Atlantic are associated with an intensification and southward displacement of the regional Hadley circulation, with anomalous northward flow between $30^{\circ} \mathrm{S}$ and $10^{\circ} \mathrm{N}$ (dashed line).

\section{Atmospheric variability II: Planetary flow regimes}

An interannual NAO index for each simulation and the NCEP-NCAR reanalysis data is plotted in Fig. 10 in terms of $500-\mathrm{hPa}$ height differences between Greenland and the Azores. The interannual variance of the NAO is realistic in ATL, and about five times greater than in CTRL, while it is not much reduced in SATL.

To understand further this increase in NAO-like in- terannual variability, we next perform a cluster analysis of the model's intraseasonal variability. The concept of weather regimes (Rheinhold and Pierrehumbert 1982) or planetary flow regimes (Legras and Ghil 1985) has been introduced in attempting to connect the observations of persistent and recurring patterns with synopticscale or planetary-scale atmospheric dynamics. Our guiding paradigm here is the hypothesis that the relatively small amplitudes of interannual-to-decadal Atlantic SST variations exert comparatively little influence on the model atmosphere's intrinsic intraseasonal modes of variability. Circulation regimes can be defined in terms of local maxima in the probability density function (PDF) of 10-day low-pass-filtered daily geopotential height maps, with bumps in the PDF corresponding to recurrent and persistent height patterns in physical space (Kimoto and Ghil 1993a,b). A regime typically persists for several days to two weeks, with rapid transitions between them associated with the nonlinearity of atmospheric dynamics. PDF maxima correspond, by definition, to relatively populated regions of the atmosphere's attractor. Slow SST variations, by contrast, can be expected to influence the less stable (more turbulent) regions of the attractor, and thus influence the frequency of the transitions into one weather regime or other. Changes in transition probabilities will manifest themselves as changes in the frequency of occurrence of circulation regimes (Legras and Ghil 1985; Horel and Mechoso 1988; Palmer 1998).

The CTRL, ATL, and SATL simulations were concatenated into a single 90-winter series of daily 700hPa geopotential height maps over the North Atlantic sector. Intraseasonal variability was next isolated by (i) subtracting winter means to remove interannual and interexperiment variability, (ii) low-pass filtering at 10 days (Blackmon and Lau 1980), and (iii) subtracting the mean seasonal cycle on a daily basis. Here we select the $700-\mathrm{hPa}$ level for ease of comparison with previous observational studies of circulation regimes (e.g., Kimoto and Ghil 1993a,b; Michelangeli et al. 1995). Regarding the comparability of variability at the $700-\mathrm{hPa}$ versus $500-\mathrm{hPa}$ levels, the leading winter-averaged EOFs were computed at each level separately and found to be very similar. The PDF of this dataset was then constructed in the subspace of its leading four EOFs, using a kernel density estimator and an angular metric in which length corresponds to pattern correlation between North Atlantic height fields in physical space. An iterative bump-hunting method was then used to locate local density maxima (Kimoto and Ghil 1993b).

The leading four covariance EOFs of low-pass-filtered daily 700-mb height data over the North Atlantic sector account for $76 \%$ of the variance, from which four regimes were obtained, using a kernel smoothing parameter of $h=35^{\circ}$. Figure 11 shows composite hemispheric maps of daily $700-\mathrm{hPa}$ height anomalies for the set of days belonging to each regime. Daily maps are assigned to a regime if they have a pattern correlation 


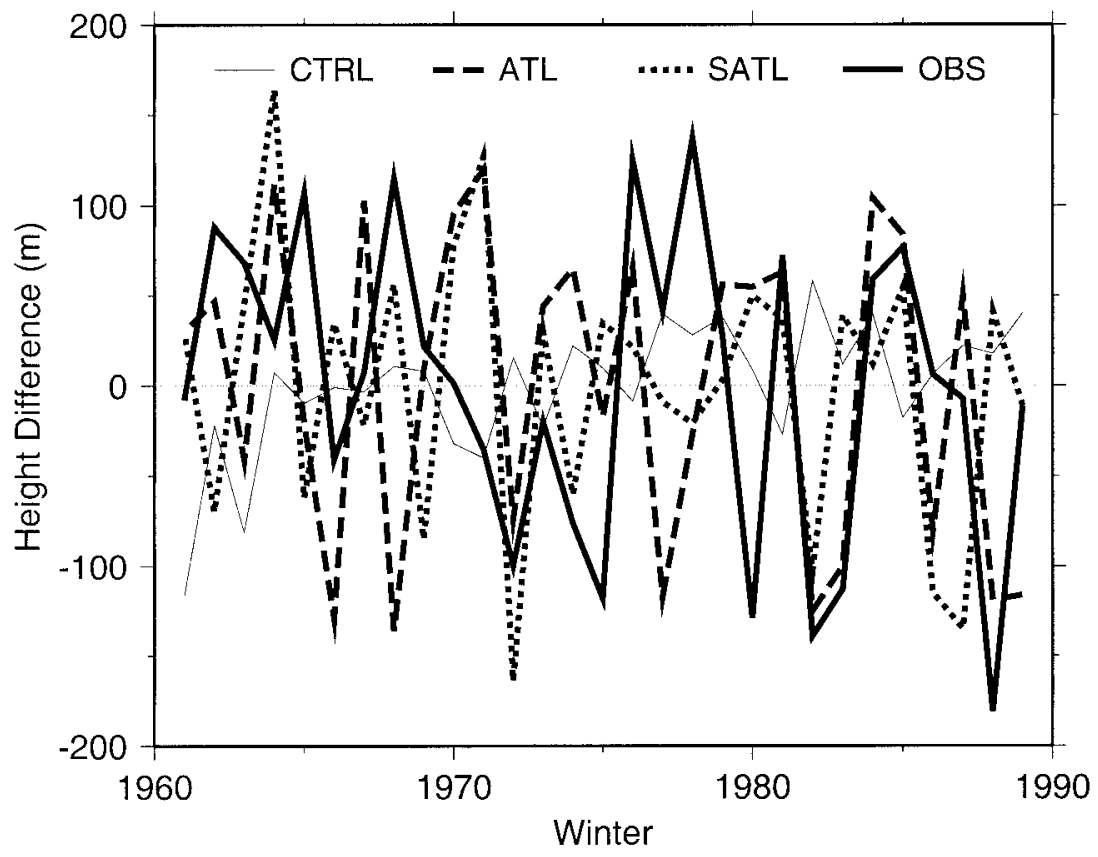

FIG. 10. The NAO index computed from each of the three GCM experiments and the NCEPNCAR reanalysis. The index is defined as the difference in DJF-mean 500-hPa heights between $\left(70^{\circ}-86^{\circ} \mathrm{N}, 60^{\circ}-30^{\circ} \mathrm{W}\right)$ and $\left(38^{\circ}-46^{\circ} \mathrm{N}, 60^{\circ} \mathrm{W}-0^{\circ}\right)$. The standard deviations of the time series are $36.7 \mathrm{~m}$ (CTRL), $86.1 \mathrm{~m}$ (ATL), $75.3 \mathrm{~m}$ (SATL), and $85.5 \mathrm{~m}$ (NCEP-NCAR reanalysis OBS). The correlation coefficients between the curves are $r=0.30$ (ATL and SATL), $r=$ 0.26 (ATL and OBS), and $r=0.07$ (SATL and OBS).

of 0.91 or greater with the central map; this strict membership criterion ensures negligible overlap between clusters and assigns $17 \%$ of all days to regimes. The use of a higher dimensional EOF subspace is impractical with the length of dataset available (Silverman 1986). However, similar regime patterns were obtained by repeating the analysis using the $K$-means clustering method as applied by Michelangeli et al. (1995), in which clusters are constructed in the subspace of the leading 10 EOFs.

The four simulated regimes in Fig. 11 exhibit Atlantic dipole patterns to varying extents, and approximate counterparts of each can be found in the observed weather-regime analyses of Kimoto and Ghil (1993b). Regimes 1 and 2 are characterized, respectively, by a trough or ridge centered near $55^{\circ} \mathrm{N}$ over the central North Atlantic, with weaker anomalies of the opposite sign centered to the southwest. This pair of regimes is similar to the persistent anomaly patterns derived from observed data by Dole (1986). Regimes 3 and 4 are more dipolar and resemble opposite phases of the observed NAO in Hurrell (1995). Thus the regime patterns are quite realistic despite the model's coarse resolution and despite its underestimation of the bandpass variance by up to $40 \%$. The leading interannual EOF in the ATL simulation (Fig. 3b) is similar to regime 3, although, unlike EOFs, the regime patterns are sign definite.

The extent to which these four intraseasonal regimes characterize interannual and interrun variability was de- termined in the following way. The low-pass-filtered 90winter combined dataset-with interannual variability retained and the mean seasonal cycle of CTRL subtracted-was projected onto the four leading intraseasonal EOFs from which the regimes in Fig. 11 were derived. The number of days in this dataset falling into the four intraseasonal regimes was found to be 1308 , which is little diminished from the 1391 days classified in the intraseasonally filtered dataset from which the regimes were derived. Thus, the circulation regimes in Fig. 11 do appear to be relevant to interannual and intersimulation variability. Figure 12 stratifies these 1308 days by experiment. While all four regimes are about equally prevalent in CTRL, regime 3 (positive NAO) occurs much more often in the ATL and SATL simulations. Decreases occur in the other three regimes, particularly regime 4 (negative NAO). The spatial structure of regime 3 (Fig. 11c) resembles the time-mean difference between the ATL and CTRL runs in Fig. 1d. This suggests that the change in the simulated stationary waves due to Atlantic SST anomalies is partly associated with an increased excitation of regime 3. Interannual variability in frequency of occurrence of regime 3 is plotted in Fig. 13. The 30-winter averages in Figs. 1d and 12 can be interpreted as large-amplitude interannual fluctuations in the prevalence of regime 3 , integrated over time. However, consistent with the interannual NAO indices in Fig. 10, the coherence between inter- 

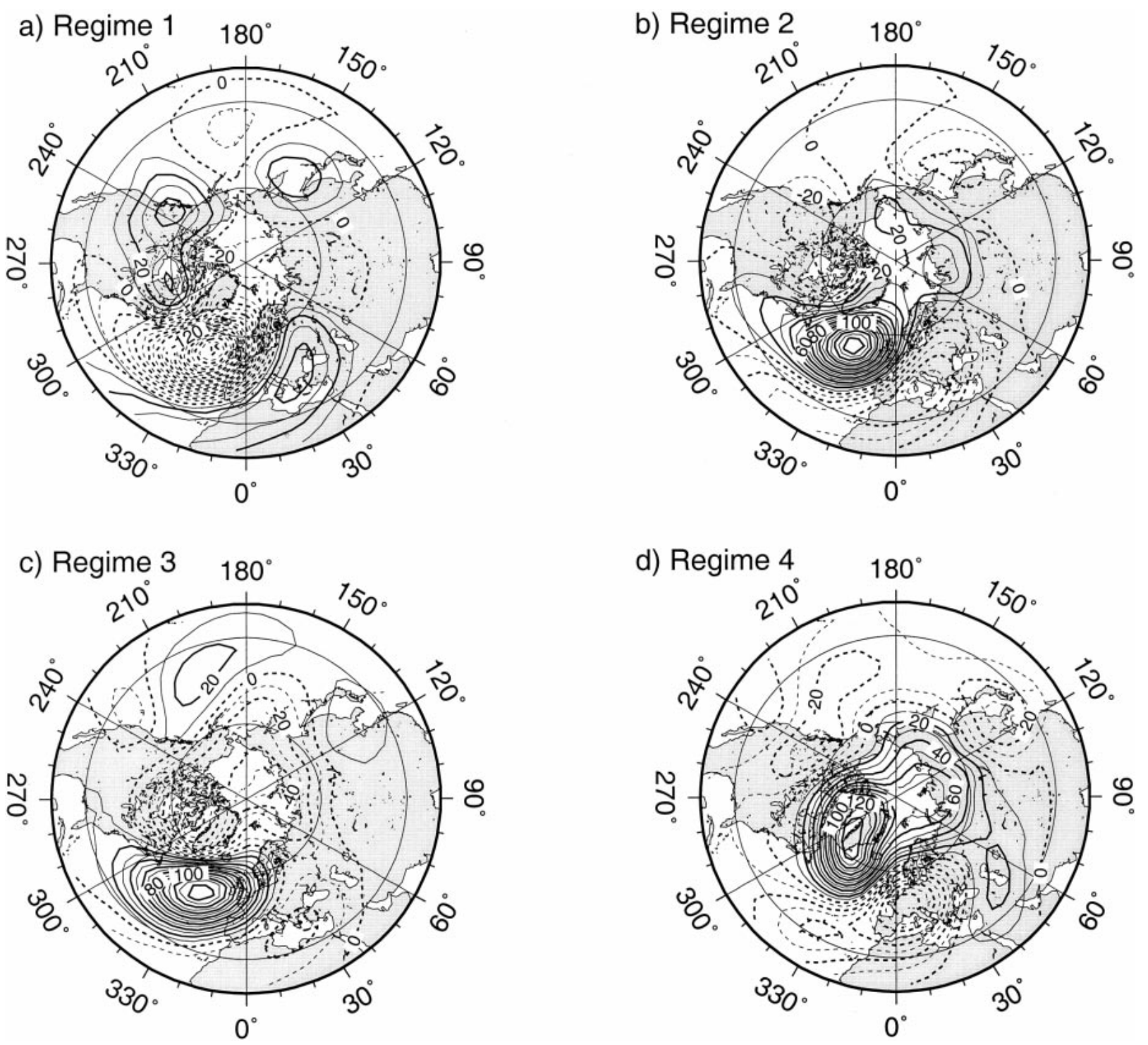

FIG. 11. Atlantic weather regimes of daily 700-hPa heights from the three GCM simulations concatenated together, filtered in the 10-90day band. Shown are anomaly composites for all days falling into each regime (contour interval $10 \mathrm{~m}$ ). The four regimes contain 422,356 , 343 , and 270 days, respectively, out of a total of 8910 .

annual fluctuations in ATL and SATL is poor, and there is clearly a large stochastic element.

The SVD analysis in section 4 suggests a dependency of the model's NAO on interannual SST anomalies over the tropical South Atlantic. We have examined the prevalence of each regime in the ATL and SATL simulations, according to an index of tropical South Atlantic SST. In ATL, regime 3 was found to be markedly more prevalent in the upper tercile of South Atlantic SST anomalies than the lower one, but this result was not highly statistically significant, and it was not reproduced in the SATL experiment (not shown). This negative result in SATL is consistent with the weaker correlations over Greenland found in the SVD in Fig. 6.

\section{Concluding remarks}

\section{a. Summary}

To investigate the influence of Atlantic SST anomalies on the wintertime atmospheric circulation over the North Atlantic, two principal 30-yr integrations were made with an atmospheric GCM: a control simulation (CTRL) forced with (seasonally varying) climatological SSTs, and a simulation with observed SSTs prescribed over the Atlantic Ocean (ATL), using climatological conditions elsewhere. A third 30-yr integration was made with observed SST variations confined to the South Atlantic (SATL). Our main results can be summarized as follows. 


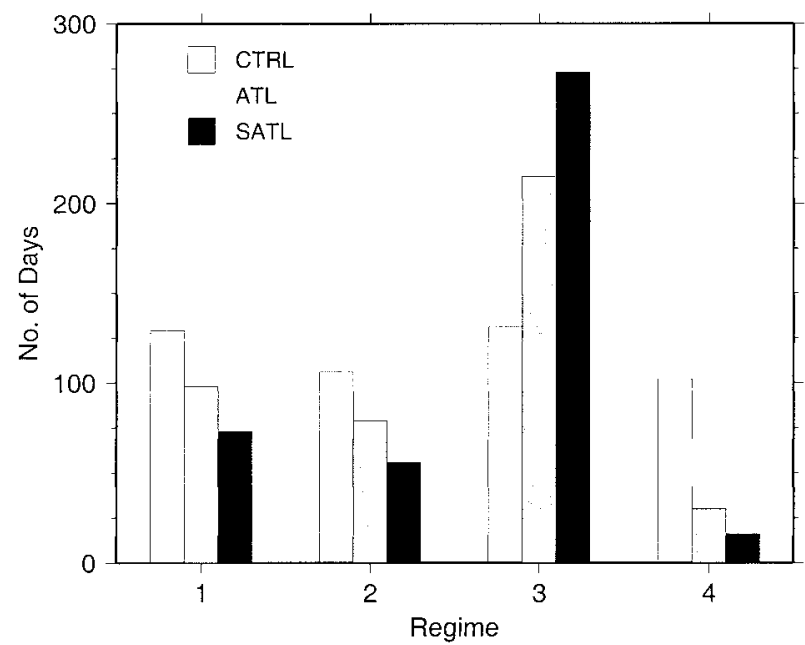

FIG. 12. Histogram of the number of days that fall into the four weather regimes, for the CTRL (white), ATL (grey), and SATL simulations (black bars), all with interannual and intersimulation variability retained.

1) Observed Atlantic SST variability produces an appreciable rectified effect on the simulated Northern Hemispheric winter-mean circulation, leading to a more realistic simulation of the stationary waves. The effect is characterized by an increase in the zonal index, with a large zonally symmetric hemispheric component and regional intensification over both the North Atlantic and North Pacific (Fig. 1d).

2) Atlantic SST variability leads to a broad increase in interannual variance of wintertime geopotential heights over the North Atlantic as well as North Pacific. Near-realistic variances are attained over the North Atlantic in the ATL simulation, while CTRL substantially underestimates them (Fig. 2); the interannual variance of the NAO in ATL is about five times greater than in CTRL (Fig. 10). Only a modest decrease in the variance of the NAO results from suppressing SST variability over the North Atlantic (SATL).

3) The leading mode of covariability in ATL between wintertime North Atlantic 500-hPa heights and Atlantic SSTs is characterized by statistically significant covariability between the model's NAO and broad SST anomalies over the South Atlantic (Fig. 4). This mode was found independently in the SATL simulation, where it is similar although weaker over the Greenland and the Arctic (Fig. 6). A similar mode was identified in observed data, too (Fig. 5).

4) The model's four intraseasonal North Atlantic weather circulations-defined via a cluster analysis of daily fields, filtered in the 10-90-day band-have spatial patterns (Fig. 11) that compare encouragingly well with observed estimates despite the model's coarse resolution (Kimoto and Ghil 1993b). The frequency of occurrence of regime 3 (positive phase

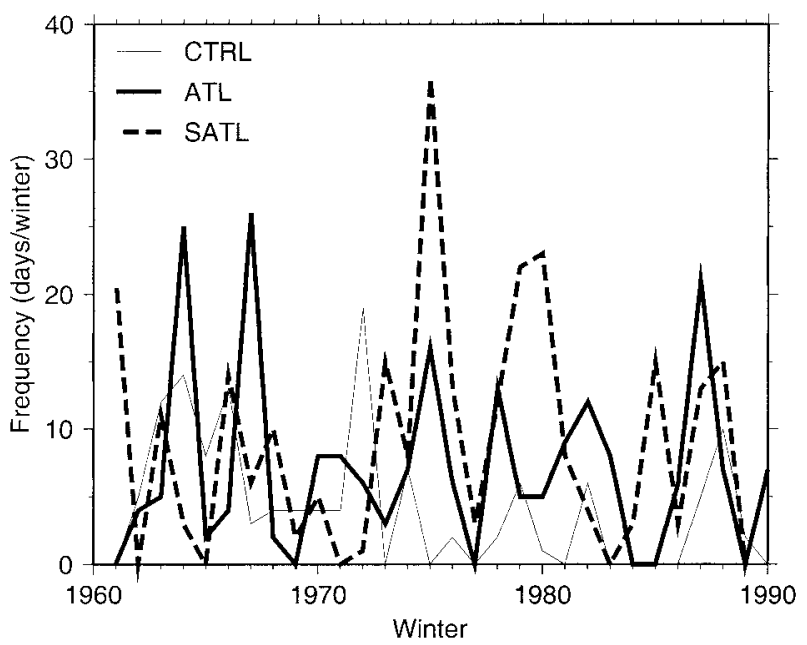

FIG. 13. Interannual variability of the frequency of occurrence of regime 3 in the three $30-\mathrm{yr}$ simulations, in terms of days per DJF winter.

NAO) is found to undergo much larger interannual variability in ATL and SATL than in CTRL.

\section{b. Discussion}

Both the ATL and SATL simulations exhibit a similar interhemispheric teleconnection that suggests the following scenario. Anomalously warm SSTs over the tropical and subtropical South Atlantic (Fig. 6a) strengthen low-level meridional temperature gradients and intensify the subtropical low-level anticyclone over the South Atlantic. Low-level convergence into the southern portion of the South American convergence zone is thus amplified while the SACZ is suppressed (Fig. 8b), giving rise to a net southward and westward shift of convective activity (Figs. 7b). The sectorial Hadley circulation emanating from Amazonia is intensified and displaced southward (Fig. 9b), giving rise to a region of anomalous upper-level convergence (Fig. 7b) over the Caribbean. The NAO anomaly obtained in the simulations may be a barotropic response to the upper-level convergence anomaly over the Caribbean. In a case study of February 1986, Hoskins and Sardeshmukh (1987) demonstrated using a barotropic model that an upper-level convergence anomaly over the Caribbean could produce a large rise in streamfunctions over the central North Atlantic. This is consistent with composite streamfunction anomalies found in the GCM (Figs. 8b).

Rajagopalan et al. (1998) have recently reported observational evidence of a significant coherence on decadal timescales, with no phase lag, between tropical South Atlantic SSTs and the NAO, with warm SSTs associated with the positive phase of the NAO, as found in our GCM. Venegas et al. (1997) have found an observed mode of covariability between SST and SLP over the South Atlantic (their mode 2) that resembles the 
GCM mode and is correlated with the NAO in the same sense.

Two additional 30-yr simulations were made with 1) observed SSTs prescribed globally (GOGA) and 2) observed SSTs limited to the tropical Pacific only (TPAC). The leading SVD mode of covariability between the North Atlantic geopotential heights and prescribed SSTs in their respective domains was an El Niño-like mode in both GOGA and TPAC experiments. No teleconnection between the NAO and South Atlantic SSTs was found in the GOGA run, which we attribute to the contaminating influence of El Niño together with the shortness of the 30-yr simulation.

Although both ATL and SATL simulations indicate statistically significant correlations between South Atlantic SSTs and the NAO, the latter is not significantly correlated between the ATL and SATL simulations, nor between either simulation and observed data (Fig. 10). These low correlations are indicative of the large amount of intrinsic NAO variability, and larger/longer ensembles of simulations are required to address the long-term predictability of the NAO. The low intersimulation NAO correlations also suggest that the model's large NAO variability and time-mean signature may simply be stochastically forced by SST variations. The occurrence of regime 3 (positive NAO) exhibits a large interannual variability in both ATL and SATL compared to CTRL, but only in ATL did increased frequency accompany warm SST anomalies over the South Atlantic.

Interannual variability is increased to near-realistic values over the North Atlantic. Our result contrasts with that of Saravanan (1998) who found no such increase in the variance of the NAO in the higher-resolution NCAR Community Climate Model when observed SSTs were prescribed, compared to climatological SST forcing. Our result is thus model (and possibly resolution) dependent. The GCM's response to Atlantic SST variations is nonlinear in character. The ATL simulation shows a strong time-mean rectified "response" to SST variations leading to a more realistic simulation of the winter stationary waves over the North Atlantic and remotely over the North Pacific (Fig. 1). The SATLminus-CTRL difference is very similar, and both are highly statistically significant. This response occurs despite the fact that the control experiment was forced by the time mean of the SST fields used in the ATL and SATL experiments. This finding suggests that the atmospheric quasi-stationary waves may have an important component associated with variations in SST. In terms of circulation regimes, this rectified response to SST anomalies over the Atlantic is associated with stronger excitation of regime 3 (Fig. 11c) by Atlantic SST variations (Fig. 12).

Acknowledgments. This work was supported by NOAA under Grants NA66GP0121 and NA86GP0289, and by DOE Grant DE-FG03-98ER62615. The GCM simulations were made at NCAR's Climate System Lab- oratory. We are grateful to P. Chang, M. Kimoto, and M. Latif for useful discussions, and to the two reviewers for their valuable critiques, which improved the manuscript. Thanks also to F. Lott for help accessing the NCEP-NCAR reanalysis data, which were provided through the NOAA Climate Diagnostics Center (http: //www.cdc.noaa.gov/).

\section{REFERENCES}

Bjerknes, J., 1964: Atlantic air-sea interactions. Advances in Geophysics, Vol. 10, Academic Press, 1-82.

Blackmon, M. L., and N.-C. Lau, 1980: Regional characteristics of the Northern Hemisphere wintertime circulation: A comparison of the simulation of a GFDL general circulation model with observations. J. Atmos. Sci., 37, 497-514.

Branstator, G. W., 1987: A striking example of the atmosphere's leading traveling pattern. J. Atmos. Sci., 44, 2310-2323.

Bretherton, C. S., C. Smith, and J. M. Wallace, 1992: An intercomparison of methods for finding coupled patterns in climate data. J. Climate, 5, 541-560.

Cayan, D. R., 1992: Latent and sensible heat flux anomalies over the northern oceans: Driving the sea surface temperature. J. Phys. Oceanogr., 22, 859-881.

Chen, W. Y., 1982: Fluctuations in Northern Hemisphere $700 \mathrm{mb}$ height field associated with the Southern Oscillation. Mon. Wea. Rev., 110, 808-823.

Cheng, X., and J. M. Wallace, 1993: Cluster analysis of the Northern Hemisphere wintertime 500-hPa height field: Spatial patterns. $J$. Atmos. Sci., 50, 2674-2696.

Cherry, S., 1997: Some comments on singular value decomposition analysis. J. Climate, 10, 1759-1761.

D'Andrea, F. D., and Coauthors, 1997: Northern Hemisphere atmospheric blocking as simulated by 15 atmospheric general circulation models in the period 1979-1988. Climate Dyn., 14, 385407.

Davis, R. E., 1976: Predictability of sea surface temperature and sea level pressure over the North Pacific. J. Phys. Oceanogr., 6, 249-266.

Deser, C., and M. L. Blackmon, 1993: Surface climate variations over the North Atlantic Ocean during winter: 1900-1989. J. Climate, 6, 1743-1754.

Dole, R. M., 1986: Persistent anomalies of the extratropical Northern Hemisphere wintertime circulation: Structure. Mon. Wea. Rev., 114, 178-207.

Graham, N. E., M. Ponater, T. P. Barnett, R. Wilde, and S. Schubert, 1994: On the roles of tropical and midlatitude SSTs in forcing interannual to interdecadal variability in the winter Northern Hemisphere circulation. J. Climate, 7, 1416-1441.

Grötzner, A., M. Latif, and T. P. Barnett, 1998: A decadal climate cycle in the North Atlantic Ocean as simulated by the ECHO coupled GCM. J. Climate, 11, 831-847.

Horel, J. D., and C. R. Mechoso, 1988: Observed and simulated intraseasonal variability of the wintertime planetary circulation. J. Climate, 1, 582-599.

Hoskins, B. J., and P. D. Sardeshmukh, 1987: A diagnostic study of the dynamics of the northern hemisphere winter of 1985-86. Quart. J. Roy. Meteor. Soc., 113, 759-778.

Hurrell, J. E., 1995: Decadal trends in the north Atlantic oscillation: Regional temperatures and precipitation. Science, 269, 676-679.

Katayama, A., 1972: A simplified scheme for computing radiative transfer in the troposphere. Numerical simulation of weather and climate. Tech. Rep. 6, 77 pp. [Available from Dept. of Atmospheric Sciences, University of California, Los Angeles, Los Angeles, CA 90095.]

Kim, Y.-J., 1996: Representation of subgrid-scale orographic effects in a general circulation model. Part I: Impact on the dynamics of simulated January climate. J. Climate, 9, 2698-2717. 
J. D. Farrara, and C. R. Mechoso, 1998: Sensitivity of AGCM simulations to modifications in the ozone distribution and refinements in selected physical parameterizations. J. Meteor. Soc. Japan, 76, 695-709.

Kimoto, M., and M. Ghil, 1993a: Multiple flow regimes in the Northern Hemisphere winter. Part I: Methodology and hemispheric regimes. J. Atmos. Sci., 50, 2625-2643.

$\longrightarrow$, and $-1993 \mathrm{~b}$ : Multiple flow regimes in the Northern Hemisphere winter. Part II: Sectorial regimes and preferred transitions. J. Atmos. Sci., 50, 2645-2673.

Kitoh, A., H. Koide, K. Kodera, S. Yukimoto, and A. Noda, 1996: Interannual variability in the stratospheric-tropospheric circulation in a coupled ocean-atmosphere GCM. Geophys. Res. Lett., 23, 543-546.

Lau, N.-C., and M. J. Nath, 1990: A general circulation model study of the atmospheric response to extratropical SST anomalies observed in 1950-79. J. Climate, 3, 965-989.

_ tropical and extratropical SST anomalies in the variability of the global atmosphere-ocean system. J. Climate, 7, 1184-1207.

— tropical Pacific ENSO events to extratropical SST anomalies. $J$. Climate, 9, 2036-2057.

Legras, B., and M. Ghil, 1985: Persistent anomalies, blocking and variations in atmospheric predictability. J. Atmos. Sci., 42, 433471.

Li, D., and K. P. Shine, 1995: A 4-dimensional ozone climatology for UGAMP models. UGAMP Internal Rep. 35. [Available from Department of Meteorology, University of Reading, 2 Earley Gate, Reading RG6 2AU, United Kingdom.]

Li, J.-L. F., and A. Arakawa, 1997: Improved simulation of PBL moist processes with the UCLA GCM. Preprints, Seventh Conf. on Climate Variations, Long Beach, CA, Amer. Meteor. Soc., 3536.

Lunkeit, F., M. Ponater, R. Sausen, M. Sogalla, U. Ulbrich, and M. Windelband, 1996: Cyclonic activity in a warmer climate. Beitr. Phys. Atmos., 69, 393-407.

Manabe, S., and F. Möller, 1961: On the radiative equilibrium and heat balance of the atmosphere. Mon. Wea. Rev., 89, 503-532.

Metz, W., and M.-M. Lu, 1990: Storm track eddies in the atmosphere and in an ECMWF T21 climate model. Beitr. Phys. Atmos., 63, 25-40.

Michelangeli, P. A., R. Vautard, and B. Legras, 1995: Weather regimes: Recurrence and quasi stationarity. J. Atmos. Sci., 52, $1237-1256$

Moses, T., G. N. Kiladis, H. F. Diaz, and R. G. Barry, 1987: Characteristics and frequency reversals in mean sea level pressure in the North Atlantic sector and their relationships to long-term temperature trends. J. Climatol., 7, 13-30.

Newman, M., and P. D. Sardeshmukh, 1995: A caveat concerning singular value decomposition. J. Climate, 8, 352-360.
Palmer, T. N., 1998: Nonlinear dynamics and climate change: Rossby's legacy. Bull. Amer. Meteor. Soc., 79, 1411-1424.

- , and Z. Sun, 1985: A modeling and observational study of the relationship between sea surface temperature in the north-west Atlantic and the atmospheric general circulation. Quart. J. Roy. Meteor. Soc., 111, 947-975.

Parker, D. E., and C. K. Folland, 1988: The nature of climatic variability. Meteor. Mag., 117, 201-210.

Peng, S., L. A. Mysak, H. Ritchie, J. Derome, and B. Dugas, 1995: The differences between early and midwinter atmospheric responses to sea surface temperature anomalies in the northwest Atlantic. J. Climate, 8, 137-157.

Rajagopalan, B., Y. Kushnir, and Y. M. Tourre, 1998: Observed decadal midlatitude and tropical Atlantic climate variability. Geophys. Res. Lett., 25, 3967-3970.

Rayner, N. A., C. K. Folland, D. E. Parker, and E. B. Horton, 1995: A new global sea-ice and sea surface temperature (GISST) data set for 1903-1994 for forcing climate models. Internal Note 69, Hadley Centre, U.K. Meteorological Office, 14 pp. [Available from Meteorological Office, London Road, Bracknell RG12 254, United Kingdom.]

Rheinhold, B. B., and R. T. Pierrehumbert, 1982: Dynamics of weather regimes: Quasi-stationary waves and blocking. Mon. Wea. Rev., 110, 1105-1145.

Robertson, A. W., M. Ghil, and M. Latif, 2000: Interdecadal changes in atmospheric low-frequency variability with and without boundary forcing. J. Atmos. Sci., in press.

Saravanan, R., 1998: Atmospheric low-frequency variability and its relationship to midlatitude SST variability: Studies using the NCAR climate system model. J. Climate, 11, 1386-1404.

Silverman, B. W., 1986: Density Estimation for Statistics and Data Analysis. Chapman and Hall, 175 pp.

Thompson, D. W. J., and J. M. Wallace, 1998: The Arctic Oscillation signature in the wintertime geopotential height and temperature fields. Geophys. Res. Lett., 25, 1297-1300.

van Loon, H., and J. C. Rogers, 1978: The seesaw in winter temperatures between Greenland and northern Europe. Part I: General description. Mon. Wea. Rev., 106, 296-310.

_ with changes in the middle troposphere in the northern winter. Mon. Wea. Rev., 109, 1163-1168.

Venegas, S. A., L. A. Mysak, and D. N. Straub, 1997: Atmosphereocean coupled variability in the South Atlantic. J. Climate, 10, 2904-2920.

Walker, G. T., and E. W. Bliss, 1932: World Weather V. Mem. Roy. Meteor. Soc., 4, 53-84.

Wallace, J. M., C. Smith, and C. S. Bretherton, 1992: Singular value decomposition of wintertime sea surface temperature and 500$\mathrm{mb}$ height anomalies. J. Climate, 5, 561-576.

Yu, J.-Y., and Coauthors, 1997: The UCLA coupled model of the atmosphere-ocean system. Proc. Mission Earth '97: Modeling and simulation of the Earth System, Phoenix, AZ, Society for Computer Simulation International, 13-18. 